Accepted for publication in Chemical Engineering Journal. Final version of the article available at: https://doi.org/10.1016/i.cej.2019.122002

(C)2019. This manuscript version is made available under the CC-BY-NC-ND 4.0 license

http://creativecommons.org/licenses/by-nc-nd/4.0/

\title{
Development of carbon-based vacuum, temperature and concentration swing adsorption post-combustion $\mathrm{CO}_{2}$ capture processes
}

\author{
M.G. Plaza* and F. Rubiera
}

Instituto Nacional del Carbón, INCAR-CSIC, C/Francisco Pintado Fe 26, 33011 Oviedo, Spain

*Corresponding author: m.g.plaza@incar.csic.es

\section{Abstract}

Vacuum, temperature and concentration swing adsorption processes, have been designed to capture $85 \%$ of the $\mathrm{CO}_{2}$ emitted by an advanced supercritical coal fired power plant of $800 \mathrm{MW}$ taken as reference, and to produce a concentrated product with $95 \%$ of $\mathrm{CO}_{2}$ (dry basis) using a sustainable carbon adsorbent inside the tubes of a tube-bundle adsorber. Indirect heat transfer is used to increase productivity and to conserve energy within the process. Two different configurations of the cyclic process have been evaluated at cyclic steady state through dynamic process simulation, using a detailed non-isothermal non-equilibrium fixed bed adsorption model that takes into consideration competitive adsorption between the main flue gas components: $\mathrm{N}_{2}, \mathrm{CO}_{2}$ and $\mathrm{H}_{2} \mathrm{O}$. Simulation results indicate that the purity and recovery constraints can be met with a specific heat duty of $2.32 \mathrm{MJ}_{\text {th }} \mathrm{kg}^{-1} \mathrm{CO}_{2}$ and a specific electric consumption of $0.66 \mathrm{MJ}_{\mathrm{e}} \mathrm{kg}^{-1} \mathrm{CO}_{2}$. The main advantage of this process is that the specific heat duty, which is lower than the benchmark amine absorption technology, could be satisfied using waste heat.

Keywords: $\mathrm{CO}_{2}$ capture, post-combustion, power plant, adsorption, simulation

\section{Introduction}

To limit global warming to $1.5^{\circ} \mathrm{C}$ above pre-industrial levels, and thus reduce the impact over the climate system, the $\mathrm{CO}_{2}$ emissions should be reduced to net zero globally around 2050 . 
Committed emissions from existing, under construction and planned coal-fired power plants, represent between 51 and $83 \%$ of the remaining carbon budget [1]. It is unlikely that these facilities will close in a time frame consistent with climate goals, so the deployment of $\mathrm{CO}_{2}$ Capture, Use and/or Storage (CCUS) technologies to decarbonize the locked-in infrastructure is urgent. Up to date, only 2 large scale CCUS facilities are operating in coal-fired power plants. In these units, $\mathrm{CO}_{2}$ is separated from the flue gas making use of absorption technology with amine solvents. The $\mathrm{CO}_{2}$ capture facility working at unit 3 of Boundary Dam coal power station, which is the first-of-its-kind, makes use of the Shell Cansolv process [2], and the Petra Nova project, which has greater capacity, makes use of MHI's KM CDR ${ }^{\mathrm{TM}}$ process [3]. The main disadvantage of amine absorption technology is its energy intensity, followed by amine deactivation, corrosion problems, and associated toxic emissions. The amine solvent is regenerated using steam; in Boundary Dam this is extracted from the power steam cycle, and in the Petra Nova project it comes from an independent cogeneration unit fueled by natural gas. It has been reported that the capture unit results in an increase of $50 \%$ in the heat rejection requirements of the power plant, which means that the availability of cooling capacity will be a major constraint for new CCS facilities [4].

Adsorption is a benign separation technology from an environmental, health and safety point of view, with no associated corrosive waste by-products or toxic emissions, that could be used to capture $\mathrm{CO}_{2}$ from a variety of sources, including coal-fired power plants, with a lower cost compared to amine technology [5]. The first pilot study that demonstrated the feasibility of the technology at a power plant was carried out in the 90 's in Japan [6]. The $\mathrm{CO}_{2}$ capture plant, which treated $1000 \mathrm{Nm}^{3} \mathrm{~h}^{-1}$ of the flue gas emitted by two coal and oil firing units, with a $\mathrm{CO}_{2}$ concentration of $10 \%$, consisted in a dehumidification unit filled with alumina, followed by a Pressure and Temperature Swing Adsorption (PTSA) stage and a PSA stage filled with Ca-X type zeolite. The targets of $90 \% \mathrm{CO}_{2}$ removal efficiency with a purity of $99 \%$ were met with a power consumption of $2.016 \mathrm{MJ}_{\mathrm{e}} \mathrm{kg}^{-1} \mathrm{CO}_{2}$, which according to the authors, could be reduced by half 
using more efficient auxiliary equipment in a full scale plant. Practicability was demonstrated by $2000 \mathrm{~h}$ of continuous operation [6]. More recently, a $\mathrm{CO}_{2}$ capture pilot plant, consisting in a dehumidifying alumina unit followed by a two successive VPSA units filled with 13X APG and activated carbon beads, respectively, has been built and demonstrated at a coal-fired power plant in China. In this pilot plant, $90.2 \%$ of $\mathrm{CO}_{2}$ was recovered with a purity of $95.6 \%$ from $35 \mathrm{Nm}^{3} \mathrm{~h}^{-1}$ of the dry flue gas ( $<0.5 \%$ relative humidity) containing $15.5-16.5 \% \mathrm{CO}_{2}$ with a total specific consumption of $2.44 \mathrm{MJ}_{\mathrm{e}} \mathrm{kg}^{-1} \mathrm{CO}_{2}$ (measured) [7]. In Poland, a mobile dual-reflux VPSA pilot plant consisting in a gas treatment section (dust removal, cooling, deSOx, deNOx, gas drying and compression) and a $\mathrm{CO}_{2}$ removal unit filled with activated carbons has been tested with $100 \mathrm{Nm}^{3} \mathrm{~h}^{-1}$ of the flue gas from the supercritical circulating fluidized-bed boiler of Łagisza power plant $\left(11.1 \% \mathrm{CO}_{2}\right)$, with a recovery of $44.6 \%$, a purity of $87.5 \%$, and a power consumption of $3.52 \mathrm{MJ}_{\mathrm{e}} \mathrm{kg}^{-1} \mathrm{CO}_{2}$ [8]. The Kawasaki $\mathrm{CO}_{2}$ capture (KCC) system is a TSA process that uses an amine-impregnated solid sorbent, which is regenerated using low-temperature steam at $60{ }^{\circ} \mathrm{C}$. A pilot $\mathrm{KCC}$ moving bed unit captured $75 \%$ of the $\mathrm{CO}_{2}$ in $820 \mathrm{Nm}^{3} \mathrm{~h}^{-1}$ of coal exhaust gas at $35{ }^{\circ} \mathrm{C}$ with a $\mathrm{CO}_{2}$ concentration of $13 \%$ with a power consumption of 1.3 $\mathrm{MJ}_{\mathrm{e}} \mathrm{kg}^{-1} \mathrm{CO}_{2}$ [9]. In another moving bed process, the advanced carbon sorbent technology (ACS), carbon beads are regenerated at $120^{\circ} \mathrm{C}$ by steam stripping. ACS has been validated with a slipstream of a pulverized coal-fired boiler with capture rates of $67 \%$ and a purity of $93 \%$ [10]. VeloxoTherm ${ }^{\mathrm{TM}}$ is an intensified TSA process that uses rotary adsorbers filled with spaced sheets of structured adsorbent, where the rapid thermal swing $\left(40-100^{\circ} \mathrm{C}\right)$ is accomplished by rotating the adsorber between the flue gas, the steam and the air sealed ducts. Field testing with a slipstream of post-baghouse coal flue gas, demonstrated to deliver $90 \%$ pure $\mathrm{CO}_{2}$ using a hydrophobic carbon adsorbent and vacuum aided regeneration ( 0.9 bar), but failed to meet the performance targets of $90 \%$ recovery and $95 \%$ purity [11]. The largest demonstration of post-combustion $\mathrm{CO}_{2}$ capture by solid sorbents up to date is the KIERDRY pilot plant, which treats a slipstream of $35,000 \mathrm{Nm}^{3} \mathrm{~h}^{-1}$ of the flue gas of a coal-fired boiler using supported 
potassium carbonate sorbents that circulate between two fluidized bed reactors: the riser, which works at $70-80{ }^{\circ} \mathrm{C}$ and the regenerator, which works at $140-200{ }^{\circ} \mathrm{C}$, with recoveries and purity above $80 \%$ and $95 \%$, respectively, and an estimated regeneration energy of $4-5 \mathrm{MJ}_{\text {th }} \mathrm{kg}^{-1}$ $\mathrm{CO}_{2}$ [12]. As can be inferred from the previous short review, adsorption-based $\mathrm{CO}_{2}$ capture processes present great design flexibility. The energy requirements vary widely with the process configuration, the adsorbent, the $\mathrm{CO}_{2}$ concentration in the feed, the $\mathrm{CO}_{2}$ capture rate, the product purity, and the pressure at which the product is delivered.

Building pilot units to demonstrate a technology is a necessary but expensive practice that is preceded by lab testing and process simulation. In the case of adsorption-based process, due to its great design flexibility, process simulation is mandatory to identify the best process configuration for a specific adsorbent and a particular application. As shown before, different types of adsorbents can be used to separate $\mathrm{CO}_{2}$ from flue gas. Among them, carbon adsorbents present the appealing advantages of hydrophobicity, easy regeneration, low cost, stability, and availability. The main disadvantage commonly attributed to carbons is their moderate adsorption capacity towards $\mathrm{CO}_{2}$. However, it has been shown through simulation that the ideal adsorbent that would lead to the lowest energy consumption in a VSA process would present a relatively low $\mathrm{CO}_{2}$ adsorption capacity [13].

In a previous work, the feasibility of a multibed heat integrated Temperature and Concentration Swing Adsorption (TCSA) post-combustion $\mathrm{CO}_{2}$ capture process was assessed trough dynamic simulation [14]. In such process, the adsorbent, which consisted in carbon monoliths, was regenerated by purging the bed with superheated steam at near atmospheric pressure; this implied a large thermal swing of $100^{\circ} \mathrm{C}$ between the adsorption temperature, $30{ }^{\circ} \mathrm{C}$, and the steam temperature, $130^{\circ} \mathrm{C}$. The use of steam above its dew point sought to limit the $\mathrm{H}_{2} \mathrm{O}$ hold up in the adsorbent, as the $\mathrm{H}_{2} \mathrm{O}$ adsorption capacity of carbon adsorbents is a strong function of the relative humidity [15]. In the present work, the use of superheated steam at subatmospheric pressures in a Vacuum, Temperature and Concentration Swing 
Adsorption (VTCSA) process is evaluated. The main advantage of the VTCSA process is that the thermal swing can be substantially reduced, and that the reduction in temperature opens the path to use waste heat as the thermal energy source, avoiding the need to extract steam from the turbines of the power plant. Different configurations of the VTCSA process have been designed and evaluated through dynamic simulation up to cyclic steady state (CSS), using a non-isothermal non-equilibrium detailed mathematical model that considers competitive adsorption between the main flue gas components: $\mathrm{N}_{2}, \mathrm{CO}_{2}$ and $\mathrm{H}_{2} \mathrm{O}$. A sequential-stage procedure was followed: first, several cycle configurations were considered to identify cycles that could satisfy a minimum of $95 \%$ purity (dry basis) and $85 \% \mathrm{CO}_{2}$ capture rate; then, the identified cycles were up scaled to treat the flue gas of an advanced supercritical coal power plant of $800 \mathrm{MW}$, which has been previously used as a common reference to compare different post-combustion technologies within HiPerCap project [16]. Finally the specific energy consumption of the $\mathrm{CO}_{2}$ capture processes that satisfied the purity and recovery constraints was calculated and compared to that of competing technologies.

\section{Materials and methods}

\subsection{Adsorbent}

The adsorbent used to run the dynamic simulations of the VTCSA cyclic processes is a microporous carbon obtained by direct oxidation of an abundant residue from the food industry: olive stones [17]. A summary of the adsorbent characteristics can be found elsewhere [18]. This adsorbent presents selectivity towards $\mathrm{CO}_{2}$ over $\mathrm{N}_{2}$ [18]. It has a moderate adsorption capacity towards $\mathrm{CO}_{2}$, but also relatively low adsorption affinity and capacity towards $\mathrm{H}_{2} \mathrm{O}$ [19]. The later feature facilitates its regeneration in VTSA processes with mild temperature swings, as it has been demonstrated with synthetic flue gas mixtures including $\mathrm{N}_{2}$, $\mathrm{CO}_{2}$ and $\mathrm{H}_{2} \mathrm{O}$ at laboratory scale [20]. These properties make this adsorbent appealing for postcombustion $\mathrm{CO}_{2}$ capture, where the flue gas is generally saturated with $\mathrm{H}_{2} \mathrm{O}$. 


\subsection{Adsorbers lay-out}

The adsorbers considered in the present work are tube bundle adsorbers, where the adsorbent is packed inside the tubes and a thermal fluid circulates externally to the tubes and axially to them. The use of indirect heat exchange entails reducing cycle time, compared to conventional temperature swing adsorption (TSA) cycles, and to recover thermal energy within the process $[14,21,22]$. Water is used as the thermal fluid due to its low cost, lack of toxicity and its adequate properties in the temperature range of operation: $30-80^{\circ} \mathrm{C}$. Thin tubes with a diameter of $3 \mathrm{~cm}$, a thin wall of $1 \mathrm{~mm}$ width, and a length of $0.7 \mathrm{~m}$ are considered to ensure fast thermal exchange and to facilitate comparison with previous results [14, 23].

\subsection{VTCSA $\mathrm{CO}_{2}$ capture process design}

Two different VTCSA cycle configurations were evaluated. In each configuration, every adsorber goes through a predefined series of steps consecutively. The following steps were considered:

1. Pressurization with feed: pressurization is carried out from the feed end $(z=0)$ while the light product end $(z=L)$ remains closed. The feed gas is the flue gas from the reference power plant cooled at a temperature $T_{L}$. During this step the column pressure increases from the lowest pressure of the cycle $\left(P_{L}\right)$ to the highest pressure of the cycle $\left(P_{H}\right)$. The duration of the pressurization step is given by the time necessary to increase the pressure from $P_{L}$ to $P_{H}$ using a constant feed flow rate. During this step, a flow rate $m_{c w}$ of cooling water is fed at $T_{L}$ from the feed end, outside the tubes, and axially to them.

2. Adsorption: the feed is fed from the feed end and the light product end remains open at $P_{H}$, which is the pressure of the flue gas of the reference power plant (without capture), to facilitate the exhaust of the decarbonized flue gas to the stack. During this step, a flow rate $m_{c w}$ of cooling water is fed at $T_{L}$ from the feed end, outside the tubes, 
and axially to them. The feed duration, which comprehends that of the pressurization and adsorption steps, determines the duration of the cycle: in this work a simple cycle with continuous feed consumption and two adsorbers working out of phase has been considered; therefore the cycle duration is twice that of the feed. The velocity of the feed determines the footprint of the adsorbent necessary to treat the full flow rate of the flue gas from the reference power plant.

3. Rinse (R): a small fraction of the $\mathrm{CO}_{2}$ product is fed from the feed end while the light product end remains open at $P_{H}$. The objective of this step is to sweep the $\mathrm{N}_{2}$ present in the bed by the end of the adsorption step and to increase the $\mathrm{CO}_{2}$ concentration in the gas and adsorbed phase at the product end $(z=0)$ in order to increase the purity in the subsequent production step. The rinse step was divided into two substeps of equal duration: R1 and R2. During R1, the outlet cooling water from the parallel adsorber, which is at an intermediate temperature $\left(T_{l}\right)$ with $T_{P}>T_{L}$, is fed from the feed end, outside the tubes, and axially to them. This entails saving thermal energy within the process. During R2, a flow rate $m_{h w}$ of heating water at a temperature $T_{H}\left(T_{l}<T_{H}\right)$ is fed from the feed end, outside the tubes, and axially to them. External heating during the rinse step intends to reduce rinse requirements and to preheat the adsorbent to avoid the condensation of steam during the subsequent production step. Prior to be fed to the adsorber, the fraction of recirculated product is heated up to $T_{I}$ and $T_{H}$ during $R 1$ and $R 2$, respectively. The practice of heating the rinse stream has previously shown to reduce power consumption [6].

4. Cocurrent Depressurization (D): the feed end closes and the bed is depressurized to an intermediate pressure $\left(P_{l}\right)$ extracting a constant molar flow rate through the light product end. This step was used as an alternative to the rinse step in one of the configurations evaluated, as it also pursues to remove the $\mathrm{N}_{2}$ present in the bed by the end of the adsorption step in order to increase the $\mathrm{CO}_{2}$ purity. Likewise to the rinse 
step, the cocurrent depressurization step is divided into two substeps of equal

duration: D1 and D2. During D1, the outlet cooling water from the parallel adsorber,

which is at a temperature $T_{1}$, is fed from the feed end, outside the tubes, and axially to them. During D2, a flow rate $m_{h w}$ of heating water at a temperature $T_{H}$, is fed from the feed end, outside the tubes, and axially to them. External heating aims to preheat the adsorbent to avoid the condensation of steam during the subsequent production step.

5. Production step: superheated steam is fed from the light product end at $T_{H}$ while the feed end is open at $P_{L}$. At the same time, a flow rate $m_{h w}$ of heating water at a temperature $T_{H}$ is fed from the feed end, outside the tubes, and axially to them. During this step $\mathrm{CO}_{2}$ is recovered from the feed end.

One of the two configurations evaluated in the present work included the rinse step, while the other included the cocurrent depressurization step.

The packed tube dimensions (diameter and length), the inlet velocity of the feed, the duration of the feed, the rinse, the cocurrent depressurization and the production steps, and the process variables $P_{H}, T_{L}, T_{H}, m_{c w}$, and $m_{h w}$, were taken as design parameters and kept equal for all the configurations evaluated in the present work. On the other hand, the flow rate of the recirculated product, the inlet flow rate of steam, and the variables $P_{L}$ and $P_{l}$, were used as decision variables.

\subsection{1. $\mathrm{CO}_{2}$ capture process by VTCSA with rinse}

The cycle schedule of the VTCSA configuration including the rinse step is presented in Figure 1. Each adsorber goes through the following steps in series: feed (pressurization and adsorption), rinse ( $R 1$ and R2), and production, completing a full cycle in $240 \mathrm{~s}$. The arrows depicted in Figure 1 represent the circulation of cooling water at $T_{1}$ between the adsorbers. 


\begin{tabular}{|c|c|c|c|c|c|}
\hline \multirow[b]{2}{*}{ Adsorber 1} & \multicolumn{5}{|c|}{ Cycle time } \\
\hline & & ED: PRESSURIZATION \& ADSORPTION & $\begin{array}{l}R \\
1\end{array}$ & $\begin{array}{l}R \\
2\end{array}$ & PRODUCTION \\
\hline & $\downarrow$ & & $\uparrow$ & & \\
\hline Adsorber 2 & $\begin{array}{l}\mathrm{R} \\
1\end{array}$ & PRODUCTION & & FEE & ZATION \& ADSORPTION \\
\hline
\end{tabular}

Figure 1. Cycle schedule of the VTCSA process with rinse.

The process flowsheet of the overall post-combustion $\mathrm{CO}_{2}$ capture process based on the VTCSA configuration with rinse is presented in Figure 2. The capture unit, delimited by a dashed line, presents just one inlet stream, the desulfurized flue gas from the reference power plant, and three outlet streams: the $\mathrm{CO}_{2}$ product, the decarbonized flue gas, and a stream of liquid water that comes from the condensate knocked out from the product and the flue gas. It is important to highlight that the flue gas from the reference power plant is continuously fed to the capture unit. Buffer tanks are used to provide a constant flow rate of decarbonized flue gas to the stack and a continuous flow rate of $\mathrm{CO}_{2}$ product to the compression stage or end user.

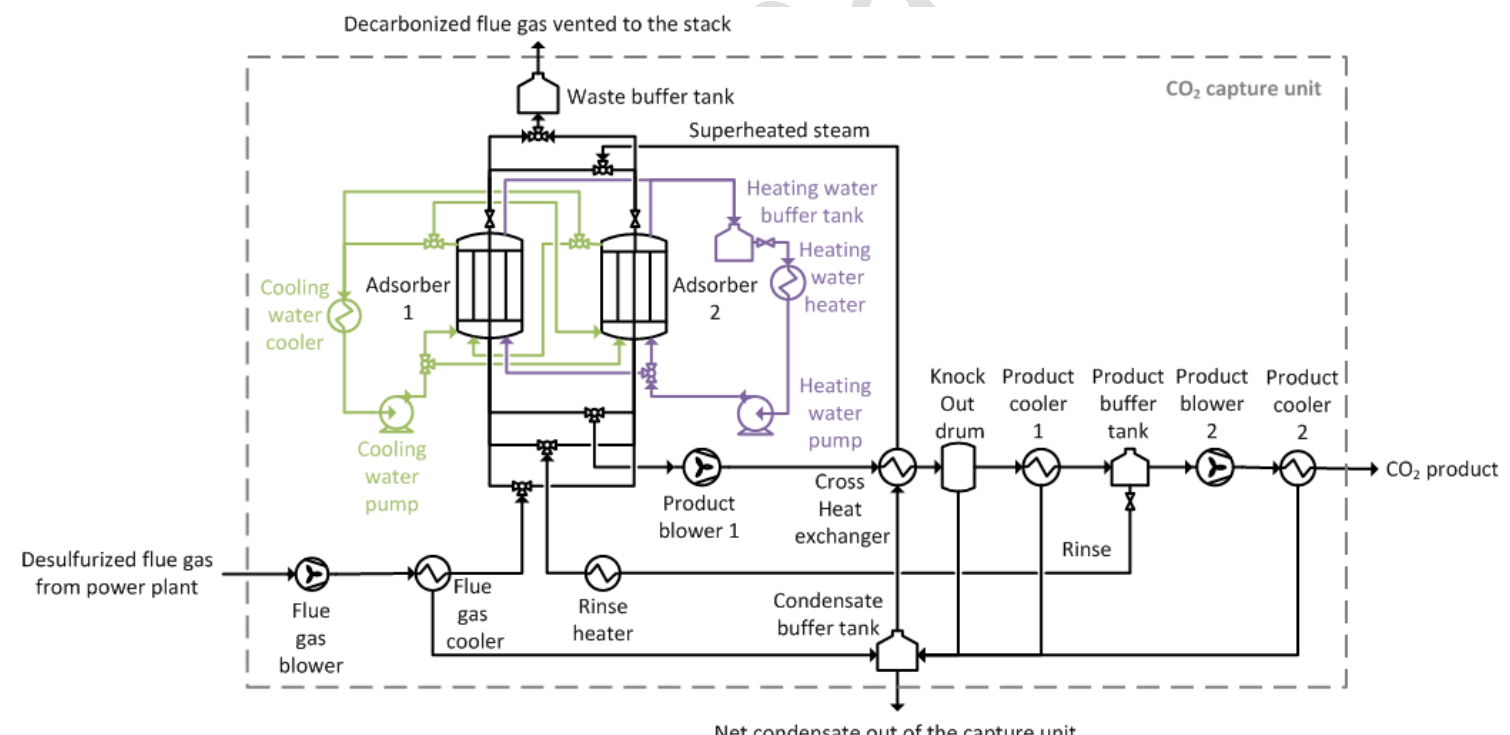

Figure 2. Simplified flow sheet of the overall post-combustion $\mathrm{CO}_{2}$ capture process based on the VTCSA configuration with rinse.

As shown in Figure 2, the desulfurized flue gas from the reference power plant, which is at 1.05 bar and $47^{\circ} \mathrm{C}[16]$, is slightly pressurized to overcome the pressure drop in the capture unit and cooled down to $T_{L}$ using available cooling water at $20.78^{\circ} \mathrm{C}[16]$. Up to this point the flowsheet is similar to that of the benchmark absorption technology. However, from this point 
onwards both processes differ. In the VTCSA process, the feed gas (desulfurized flue gas at $T_{L}$ ) switches at regular intervals (every half cycle time) between two adsorbers that operate out of phase by means of an automated valve system. Each of the adsorbers goes continuously through the cycle schedule depicted in Figure 1. The effluent produced during the adsorption step and the rinse steps, which is rich in $\mathrm{N}_{2}$, is vented to the stack. The outlet stream of the production step is a hot mixture of $\mathrm{CO}_{2}$ and $\mathrm{H}_{2} \mathrm{O} . \mathrm{H}_{2} \mathrm{O}$ is easily separated by condensation, leaving a high purity $\mathrm{CO}_{2}$ product. A small fraction of the product is recirculated, and the rest is pressurized up to 2 bar and cooled down to circa $30^{\circ} \mathrm{C}$ to facilitate comparison with the absorption technology reference case, that delivers the $\mathrm{CO}_{2}$ product in such conditions to the compression stage [16]. As shown in Figure 2, the product pressure is increased from $P_{L}$ to 2 bar in two stages, as this configuration leads to a lower energy consumption. The condensate knocked out from the wet product is used to produce the steam required to regenerate the adsorbent, closing the loop. To save thermal energy within the overall process, the enthalpy of the hot wet product is used to generate the steam (see the cross heat exchanger in Figure 2). Note that the cross heat exchanger is placed after Product blower 1 to exploit part of the waste heat generated during the mechanical compression of the product.

\subsection{2. $\mathrm{CO}_{2}$ capture process by VTCSA with cocurrent depressurization}

The cycle schedule of the VTCSA configuration with cocurrent depressurization is shown in Figure 3. Each adsorber goes through the following steps in series: feed (pressurization and adsorption), cocurrent depressurization (D1 and D2), and production, completing a full cycle in 240 s. The arrows depicted in Figure 3 represent the circulation of water between the adsorbers at $T_{1}$. This is similar to the previous configuration except for the substitution of the rinse step by the cocurrent depressurization step. 


\begin{tabular}{|c|c|c|c|c|c|c|}
\hline \multirow[b]{2}{*}{ Adsorber 1} & \multicolumn{6}{|c|}{ Cycle time } \\
\hline & \multicolumn{3}{|c|}{ FEED: PRESSURIZATION \& ADSORPTION } & $\begin{array}{l}\text { D } \\
1\end{array}$ & $\begin{array}{l}D \\
2\end{array}$ & PRODUCTION \\
\hline & $\downarrow$ & & & $\uparrow$ & & \\
\hline Adsorber 2 & \begin{tabular}{l|} 
\\
1
\end{tabular} & $\begin{array}{l}\text { D } \\
2\end{array}$ & PRODUCTION & & FEE & ZATION \& ADSORPTION \\
\hline
\end{tabular}

Figure 3. Cycle schedule of the VTCSA process with cocurrent depressurization.

The flowsheet of the overall post-combustion $\mathrm{CO}_{2}$ capture process based on the VTCSA configuration with cocurrent depressurization is shown in Figure 4. This is similar to that of Figure 2 except for the lack of product recirculation, the absence of the Rinse heater, and the presence of the Waste blower, which is necessary to rise the pressure of the product from the cocurrent depressurization, which is rich in $\mathrm{N}_{2}$, from $\mathrm{P}_{1}$ to 1.05 bar in order to discharge it to the stack.

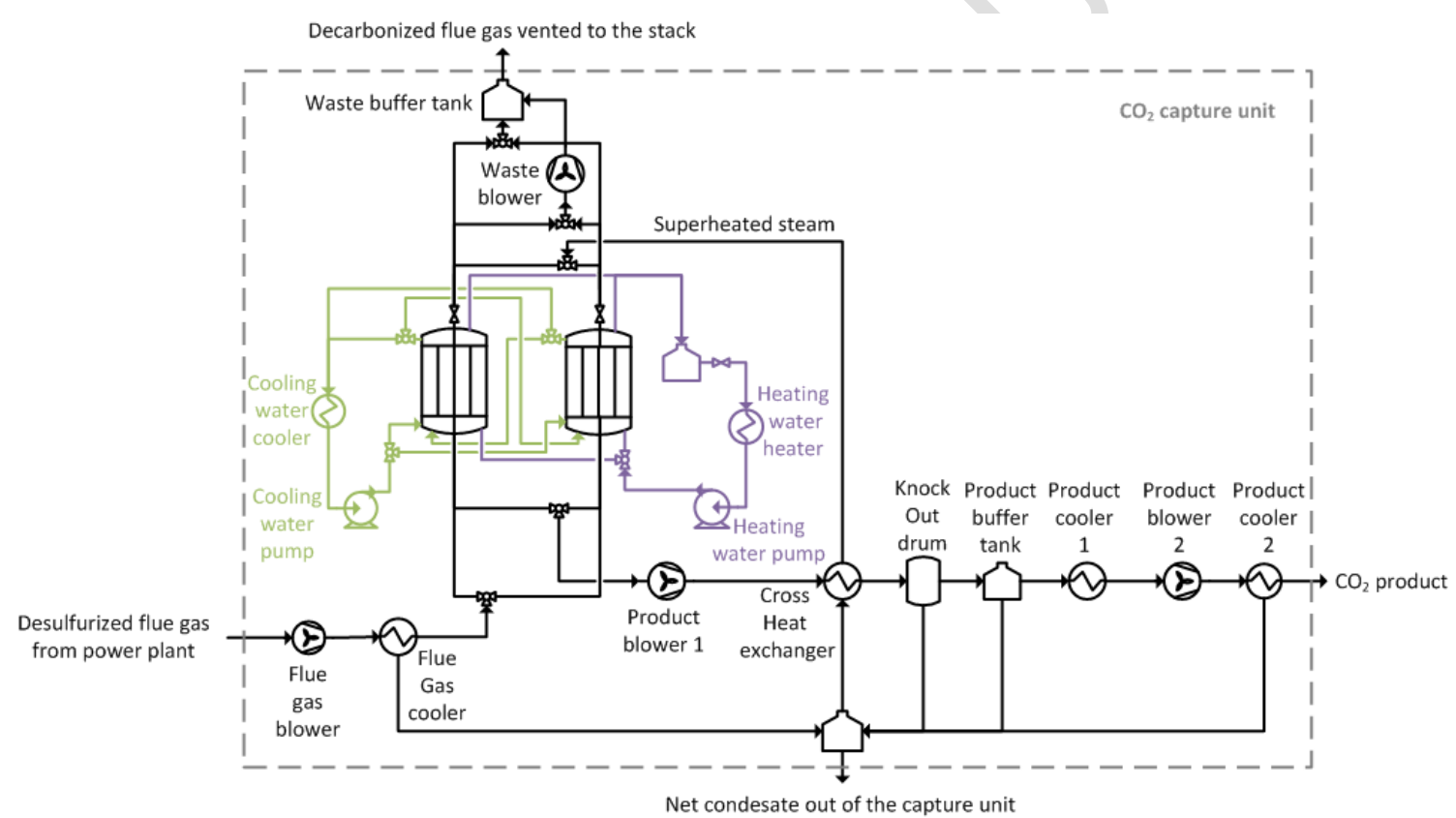

Figure 4. Simplified flow sheet of the overall post-combustion $\mathrm{CO}_{2}$ capture process based on the VTCSA configuration with cocurrent depressurization.

\subsection{Simulation of the VTCSA configurations}

The flue gas from the reference power plant contains mainly $\mathrm{N}_{2}, \mathrm{CO}_{2}$, and $\mathrm{H}_{2} \mathrm{O}$, with lesser amounts of $\mathrm{O}_{2}$, and $\mathrm{Ar}$ and trace amounts of $\mathrm{SO}_{2}$ [16]. To reduce the computational effort, only $\mathrm{CO}_{2}, \mathrm{~N}_{2}$ and $\mathrm{H}_{2} \mathrm{O}$ were considered in the dynamic simulations. As $\mathrm{O}_{2}$ and $\mathrm{Ar}$ are expected to 
behave similarly than $\mathrm{N}_{2}$ [24], the molar fraction of $\mathrm{N}_{2}$ was calculated by difference. The presence of trace amounts of sulfur oxides are not expected to be a problem for carbon adsorbents $[11,25]$.

A single tube with a jacket heat exchanger was used for simulation purposes. It is assumed that every tube in the bundle would behave similarly.

The cyclic model is based on a one dimension non-isothermal non-equilibrium fixed bed adsorption model that has been previously validated with experimental results obtained in a laboratory scale fixed-bed VPTSA adsorption unit with synthetic flue gas mixtures containing $\mathrm{N}_{2}, \mathrm{CO}_{2}$ and $\mathrm{H}_{2} \mathrm{O}$ using the same adsorbent [18-20]. This takes into consideration competitive adsorption between $\mathrm{N}_{2}, \mathrm{CO}_{2}$ and $\mathrm{H}_{2} \mathrm{O}$, making use of the Ideal Adsorption Solution (IAS) theory [26]. IAS presents the advantage that it entails using different pure equilibrium models for each adsorbate. This is relevant when dealing with $\mathrm{H}_{2} \mathrm{O}$ adsorption on carbons, which presents a characteristic adsorption mechanism radically distinct from that of $\mathrm{CO}_{2}$ and $\mathrm{N}_{2}$. The equilibrium of adsorption of pure $\mathrm{CO}_{2}$ and $\mathrm{N}_{2}$ is modeled making use of the Toth equation, whereas the equilibrium of adsorption of pure $\mathrm{H}_{2} \mathrm{O}$ is modeled through the Extended Cooperative Multimolecular Sorption theory [27]. The equilibrium model equations and parameters can be found elsewhere $[18,19]$.

The material and energy balances of the model account for three different phases: the solid adsorbent, the gas phase, and the heat transfer fluid. The following assumptions were made: the gas flow within the packed tubes can be described as axially dispersed plug flow; the pressure of the gas phase inside the packed tubes is calculated locally as a function of the gas velocity using the Ergun equation; radial dispersion within the tubes is negligible; the solid linear driving force approximation is valid; a film resistance model is used to represent the heat transfer between the gas and the adsorbent; the adsorbers are thermally insulated from ambient air; the heat transfer medium only exchanges heat with the gas phase, and the overall 
Accepted for publication in Chemical Engineering Journal. Final version of the article available at: https://doi.org/10.1016/i.cej.2019.122002

heat transfer coefficient between the gas phase and the heat transfer medium is considered constant.

The dynamic simulations of the VTCSA configurations evaluated were carried out with Aspen Adsorption V8.8 up to CSS (the simulation was automatically paused once the relative difference between the total loading and the solid temperature at the end of each cycle and those of the previous cycle fell below 0.00001$)$. The model is constituted by a set of partial differential equations, ordinary differential equations and algebraic equations, together with the appropriate initial and boundary conditions, which fully describe the process. The spatial derivatives are discretized using the upwind differentiating scheme with 100 nodes, resulting in a set of ordinary differential equations and algebraic equations, which is solved simultaneously using the method of lines. The non-ideality of the gas phase is accounted for by the compressibility factor, which is calculated via Aspen's properties interface, together with other physical properties, using the PSRK method.

The adsorber model is configured as a one-dimension, vertical, reversible flow setter, with a single layer of adsorbent, and a one-phase jacket heat exchanger. The momentum balance option used is Convection with estimated dispersion. The kinetic model option used is Lumped resistance with solid linear driving force approximation and a user-defined submodel for the mass transfer coefficient that takes into consideration its temperature dependency (see supporting information for further details). The options selected for the equilibrium of adsorption are user submodel with IAS and partial pressure dependency. The user-defined equilibrium model equations and the parameters of the pure component equilibrium models can be found elsewhere $[18,19]$. The energy balance includes gas and solid conduction; the heat of adsorption and the heat of adsorbed phases are considered constant; the heat transfer coefficient between the gas and the adsorbent is Estimated locally; the effective conductivity of the gas phase is also calculated locally Based on axial dispersion, and the heat transfer to environment is considered negligible (Adiabatic). 
The Cyclic organizer tool was used to define the steps of the VTCSA processes, which have been described in Sections 2.3.1 and 2.3.2. All the steps are time driven. The cyclic flowsheets used to simulate the VTCSA processes can be found in the supporting information. Linear nonreversible gas valve models were used to connect the inlet process streams (feed, rinse and steam) and the outlet process streams (decarbonized waste gas produced during adsorption, W1, and decarbonized waste gas produced during cocurrent blowdown, W2) to the adsorber. The feed, rinse and steam valves (VF1, VR1, and VS1, respectively) are used to set the flowrate of the feed, the rinse and the steam streams during the feed, rinse and production steps, respectively, and are closed during the rest of the cycle. The decarbonized flue gas valve, VW1, is closed during the whole cycle except during adsorption, when it is open. Valve VW2 is closed during the whole cycle except during cocurrent blowdown, when it is used to provide a constant flowrate of decarbonized gas. The product valve, VP1, is closed during the whole cycle except during production, when it is open. The inlet temperature of the adsorber's cooling/heating water is a boundary condition that changes between the steps, as described in Sections 2.3.1 and 2.3.2. $T_{L}$ and $T_{H}$ are design parameters. However, $T_{1}$ is a process variable. Aspen Adsorption V8.8 does not entail the automatic recirculation of the thermal fluid between the adsorbers, so in order to run the simulations, an iterative procedure was followed: (i) a simulation of the VTCSA process was carried out until CSS using an initial guess of $T_{1}$; (ii) then, the average value of the outlet temperature of the water exiting an adsorber during the first $10 \mathrm{~s}$ of the feed step at CSS was calculated; (iii) a new simulation was carried out until CSS using the latter value as the new guess of $T_{1}$. This procedure was repeated until no difference was observed in $\mathrm{T}_{1}$ (or $\mathrm{CO}_{2}$ capture rate or $\mathrm{CO}_{2}$ purity) between two consecutive runs. A likewise procedure was followed for the composition of the rinse stream: (i) a simulation of the VTCSA process was carried out until CSS using an initial guess of the composition of the rinse stream; (ii) then, the composition of the rinse stream was calculated, and used as inlet to run a new VTCSA simulation until CSS. This protocol was followed until no 
Accepted for publication in Chemical Engineering Journal. Final version of the article available at: https://doi.org/10.1016/i.cej.2019.122002

changes were observed between two consecutive runs. Average values of the molecular diffusivities, calculated using the Wilke method [28] and the Chapman-Enskog theory [29], and the heat capacities of the adsorbent and the adsorbed phase were considered for each step.

The relative humidity of the gas phase was calculated to check that no condensation occurred in the bed during the VTCSA cycles.

The design parameters of the VTCSA process used to run the simulations are summarized in Table 1. 
Table 1. Design parameters of the VTCSA process

\begin{tabular}{|c|c|c|c|c|}
\hline \multicolumn{3}{|l|}{ Parameter } & Value & Units \\
\hline \multicolumn{3}{|c|}{ Length of the tubes packed with the adsorbent $(\mathrm{L})$} & 0.7 & $\mathrm{~m}$ \\
\hline \multicolumn{3}{|c|}{ Diameter of the tubes packed with the adsorbent } & 0.03 & $\mathrm{~m}$ \\
\hline \multicolumn{3}{|c|}{$\begin{array}{l}\text { Wall width between the adsorbent and the heat transfer } \\
\text { fluid }\end{array}$} & 1 & $\mathrm{~mm}$ \\
\hline \multicolumn{3}{|l|}{ Average adsorbent particle radius } & 1.08 & $\mathrm{~mm}$ \\
\hline \multicolumn{3}{|c|}{$\begin{array}{l}\text { Overall heat transfer coefficient between the gas phase } \\
\text { and the heat exchange medium }\end{array}$} & 2000 & 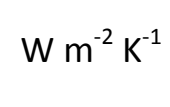 \\
\hline \multirow{6}{*}{$\begin{array}{l}\text { Desulfurized flue gas from the } \\
\text { reference power plant }\end{array}$} & \multicolumn{2}{|c|}{ Molar flow rate } & $27217^{\mathrm{a}}$ & $\mathrm{mol} \mathrm{s}^{-1}$ \\
\hline & \multicolumn{2}{|c|}{ Pressure } & $1.05^{\mathrm{a}}$ & bar \\
\hline & \multicolumn{2}{|l|}{ Temperature } & $47^{\mathrm{a}}$ & ${ }^{\circ} \mathrm{C}$ \\
\hline & Composition & $\mathrm{CO}_{2}$ & $13.60^{\mathrm{a}}$ & $\% \mathrm{~mol}$ \\
\hline & & $\mathrm{H}_{2} \mathrm{O}$ & $10.16^{\mathrm{a}}$ & $\% \mathrm{~mol}$ \\
\hline & & $\mathrm{N}_{2}$ & $76.24^{b}$ & $\% \mathrm{~mol}$ \\
\hline \multirow[t]{4}{*}{ Feed } & \multicolumn{2}{|c|}{ Temperature $\left(T_{L}\right)$} & 30.78 & ${ }^{\circ} \mathrm{C}$ \\
\hline & Composition & $\mathrm{CO}_{2}$ & 14.49 & $\% \mathrm{~mol}$ \\
\hline & & $\mathrm{H}_{2} \mathrm{O}$ & 4.23 & $\% \mathrm{~mol}$ \\
\hline & & $\mathrm{N}_{2}$ & 81.27 & $\% \mathrm{~mol}$ \\
\hline \multicolumn{3}{|c|}{$\begin{array}{l}\text { Pressure of the decarbonized flue gas vented to the stack } \\
\left(P_{H}\right)\end{array}$} & 1.05 & bar \\
\hline \multicolumn{3}{|c|}{ Total duration of the feed step } & 120 & $\mathrm{~s}$ \\
\hline \multicolumn{3}{|c|}{$\begin{array}{l}\text { Total duration of the rinse (or cocurrent } \\
\text { depressurization) step }\end{array}$} & 20 & $\mathrm{~s}$ \\
\hline \multicolumn{3}{|l|}{ Duration of the production step } & 100 & s \\
\hline \multicolumn{3}{|c|}{ Superficial velocity of the feed gas at the adsorber inlet } & 0.27 & $\mathrm{~m} \mathrm{~s}^{-1}$ \\
\hline \multicolumn{3}{|l|}{ Inlet temperature of steam $\left(T_{H}\right)$} & 80 & ${ }^{\circ} \mathrm{C}$ \\
\hline \multicolumn{3}{|c|}{$\begin{array}{l}\text { Temperature of the product at the outlet of Product } \\
\text { cooler } 1\end{array}$} & 30.78 & ${ }^{\circ} \mathrm{C}$ \\
\hline \multicolumn{3}{|c|}{$\begin{array}{l}\text { Temperature of the final product at the outlet of Product } \\
\text { cooler } 2\end{array}$} & 30.78 & ${ }^{\circ} \mathrm{C}$ \\
\hline \multicolumn{3}{|c|}{ Pressure at the outlet of Product blower 1} & 1.1 & bar \\
\hline \multicolumn{3}{|c|}{$\begin{array}{l}\text { Pressure of the final } \mathrm{CO}_{2} \text { product delivered to the } \\
\text { compression stage }\end{array}$} & 2.0 & bar \\
\hline \multicolumn{3}{|c|}{$\begin{array}{l}\text { Total flow rate of cooling water required by the } \\
\text { adsorbers }\left(m_{c w}\right)\end{array}$} & 19150 & $\mathrm{~kg} \mathrm{~s}^{-1}$ \\
\hline \multicolumn{3}{|c|}{$\begin{array}{l}\text { Average flow rate of heating water required by the } \\
\text { adsorbers }\left(<m_{h w}>\right)\end{array}$} & $17554^{c}$ & $\mathrm{~kg} \mathrm{~s}^{-1}$ \\
\hline
\end{tabular}

${ }^{\mathrm{a}}[16] ;{ }^{\mathrm{b}}$ Calculated by difference; ${ }^{\mathrm{c}}$ averaged by cycle time

Table 2 summarizes the lower and upper bounds of the decision variables used to run the simulations of the evaluated VTCSA configurations. 
Table 2. Upper and lower bounds for the decision variables used to simulate the VTCSA configurations

\begin{tabular}{lll}
\hline Process variables & Value & Units \\
\hline Low pressure $\left(\mathrm{P}_{\mathrm{L}}\right)$ & $0.2-0.3$ & bar \\
Intermediate pressure $\left(\mathrm{P}_{\mathrm{l}}\right)$ & $0.47-0.74$ & bar \\
Rinse to feed molar ratio & $0.02-0.05$ & - \\
Steam to feed molar ratio & $0.09-0.24$ & - \\
\hline
\end{tabular}

2.4. Upscaling and evaluation of the performance of the VTCSA post-combustion $\mathrm{CO}_{2}$ capture processes

The results from the dynamic simulations of the VTCSA cycles at CSS were used to upscale the processes to treat the full molar flow rate of the flue gas from the reference power plant. The closure of the global mass balance to the $\mathrm{CO}_{2}$ capture unit (delimited by the dashed lines in Figures 2 and 4) was checked for every case evaluated.

The performance of the overall post-combustion $\mathrm{CO}_{2}$ capture process is assessed in terms of the $\mathrm{CO}_{2}$ purity of its final product in dry basis, its $\mathrm{CO}_{2}$ capture rate, its productivity and its energy consumption. The purity, the capture rate and the productivity are defined by Equations 1, 2 and 3, respectively.

$\mathrm{CO}_{2}$ purity of the product $(\% \mathrm{~mol}, \mathrm{db})=\frac{\text { mol of } \mathrm{CO}_{2} \text { in the product }}{\text { total mol of product appart from } \mathrm{H}_{2} \mathrm{O}} \times 100$

Capture rate $(\%)=\frac{\text { mass flow rate of } \mathrm{CO}_{2} \text { in the final product }}{\text { mass flow rate of } \mathrm{CO}_{2} \text { fed with the flue gas }} \times 100$

Productivity $\left(\frac{\mathrm{kg} \mathrm{CO}_{2}}{\mathrm{~kg} \text { of adsorbent } \times h}\right)=\frac{\text { mass flow rate of } \mathrm{CO}_{2} \text { in the final product }}{\text { total mass of adsorbent }}$

The energy consumption of the auxiliary equipment represented in Figures 2 and 4 was calculated with Aspen Plus V8.8 using the cycle-averaged results from the dynamic simulations of the VTCSA process at CSS. The flowsheets used can be found in the supporting information. The total heat duty of every configuration evaluated was calculated from the sum of the heat duty of the heating water heater and the rinse heater (if present). The total cooling duty was calculated from the sum of the cooling duties of the flue gas cooler, the cooler of the 
Accepted for publication in Chemical Engineering Journal. Final version of the article available at: https://doi.org/10.1016/i.cej.2019.122002

absorbers' cooling water, and the two product coolers. The electricity requirements were calculated from the sum of the consumption of the flue gas blower, the waste blower (if present), the two product blowers, and the centrifugal pumps required to circulate the cooling and heating water to and from the adsorbers. For the blowers, an isentropic efficiency of $75 \%$ was assumed and a mechanical efficiency of $95 \%$; for the centrifugal pumps an efficiency of $80 \%$ and a driver efficiency of $95 \%$. A pressure drop of 0.4 bar was assumed for the circulation of the heating and cooling water through the adsorbers; and a pressure drop of $2 \%$ of the inlet pressure was assumed for the circulation of the gas phase in the coolers, heaters, and cross heat exchanger. The pressure drop in the adsorbent bed was calculated within the VTCSA simulation using the Ergun Equation, as stated in the previous section; a safe margin was added for unaccounted pressure drop in the gas distribution system. A minimum temperature approach of $10^{\circ} \mathrm{C}$ was assumed for the cross heat exchanger and the coolers. The latter are cooled using the reference power plant's cooling water, which is delivered at $20.78^{\circ} \mathrm{C}$ and returned at $30.53{ }^{\circ} \mathrm{C}$. These utilities' specifications have been set in agreement with previous studies $[14,16,23]$ to facilitate technology comparison.

The specific energy requirements of the overall post-combustion $\mathrm{CO}_{2}$ capture process are calculated per $\mathrm{kg}$ of $\mathrm{CO}_{2}$ captured in order to facilitate comparison with other post-combustion processes. However, the comparison of the energy performance of different post-combustion technologies is not straightforward, as they can make use of different sources of energy: electricity, low-temperature waste heat, and steam extracted from the turbines. The latter reduces the output power of the plant, while the first reduces the net output. On the other hand, the exploitation of unused waste heat sources is highly desirable as this does not reduce the net power output of the plant. In order to compare the energy penalty of post-combustion technologies that make use of different energy sources on a fair basis, specific terms have been introduced in the literature. Among them, we find the Specific Energy Penalty of Avoided $\mathrm{CO}_{2}$ (SEPAC), which is defined by Equation 4 [16]: 


$$
S E P A C=\frac{N E O_{r e f}-N E O}{\phi_{C O_{2}{ }_{2 e f}}-\phi_{C O}}
$$

where $N E O$ is the net electric output of the power plant in $\mathrm{MW}_{\mathrm{e}}, \phi_{\mathrm{CO}_{2}}$ is the emitted flow of $\mathrm{CO}_{2}$ in $\mathrm{kg} \mathrm{s}^{-1}$, and ref states for the reference power plant without capture.

SEPAC measures the reduction in the net power output of the reference power plant due to capture, normalized by the amount of $\mathrm{CO}_{2}$ avoided. In the present work, SEPAC is used to compare the energy performance of the VTCSA process with that of the benchmark technology using a common reference power plant and a similar set of assumptions. The SEPAC value for the reference power plant integrated with a second generation absorption-based $\mathrm{CO}_{2}$ capture process, and the value of $\mathrm{NEO}_{\text {ref }}$ and $\phi_{\mathrm{CO}_{2} \text { ref }}$, were taken from literature [16]. A priori, to estimate $\mathrm{NEO}$ and $\phi_{\mathrm{CO}_{2}}$, the capture plant should be integrated into the reference power plant [16]. However, the modelling of the reference power plant is out of the scope of the present work. The SEPAC value of the VTCSA post-combustion $\mathrm{CO}_{2}$ capture process has been calculated assuming that the low-temperature heat demand of the process can be entirely satisfied using unused waste heat sources. I.e.: the net output of the reference power plant with VTCSA capture is assumed to be that of the reference power plant without capture minus the electric power required by the capture unit.

\section{Results and discussion}

\subsection{Evaluation of the performance of the VTCSA post-combustion capture process}

The purity-recovery Pareto fronts obtained for the two VTCSA configurations evaluated in the present work are presented in Figure 5. 


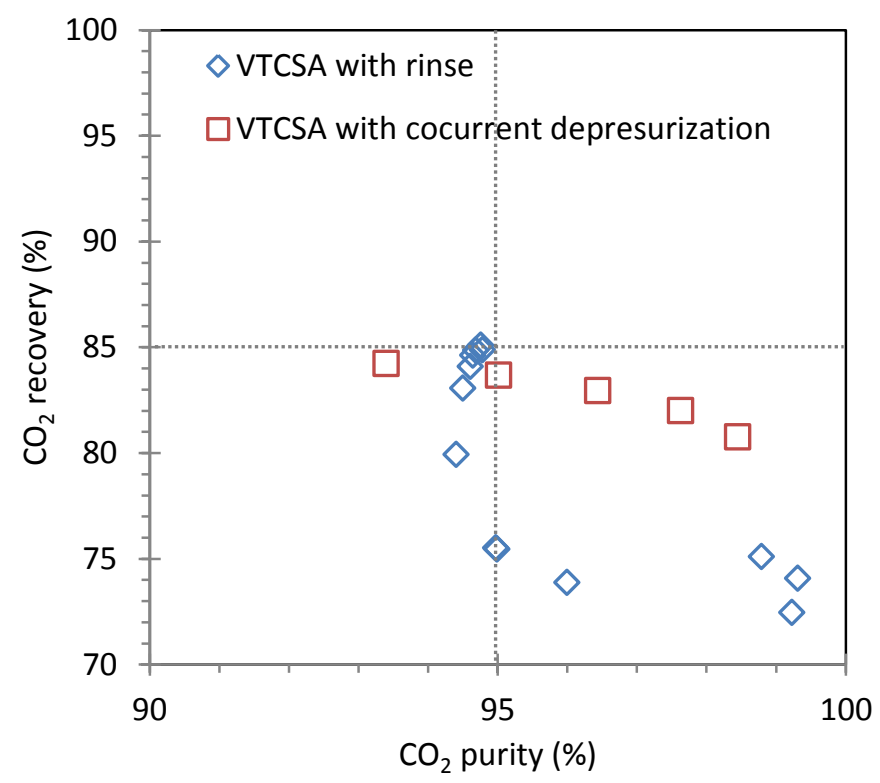

Figure 5. Purity-recovery Pareto fronts for the two VTCSA configurations explored in this study.

As can be seen from the figure, the VTCSA configuration with cocurrent depressurization can provide high purities with recoveries above $80 \%$, but fails to satisfy the $85 \%$ capture rate and 95\% purity constraints simultaneously. On the other hand, the Pareto front of the VTCSA configuration with rinse presents several points that satisfy the previous requirements. These points correspond to the lowest bound of $P_{L}$ evaluated.

The process performance parameters of the VTCSA post-combustion $\mathrm{CO}_{2}$ capture process that satisfies the purity and recovery constrains with the lowest specific energy demand are summarized in Table 3. Another three post-combustion $\mathrm{CO}_{2}$ capture processes have been included in the table for comparison purposes: an advanced absorption case taken as the reference case within HiPercap project (CESAR1) [16], a TCSA process based on structured carbon monoliths [14], and a VTSA process that makes use of the same biomass-based carbon adsorbent [23]. These processes have been developed for the same reference power plant using the common set of assumptions described in Section 2.4. 
Table 3. Comparison of post-combustion $\mathrm{CO}_{2}$ capture processes using a common reference power plant and a similar set of assumptions.

\begin{tabular}{|c|c|c|c|c|c|}
\hline Parameter & $\operatorname{VTCSA}^{\mathrm{a}}$ & VTSA $^{b}$ & $\operatorname{TCSA}^{\mathrm{c}}$ & $\begin{array}{l}\text { Advanced } \\
\text { solvent }^{d}\end{array}$ & Units \\
\hline Purity of the $\mathrm{CO}_{2}$ product & 95 & 95 & 96 & $\geq 95$ & $\%$ mol, dry basis \\
\hline $\mathrm{CO}_{2}$ capture rate & 85 & 85 & 85 & 90 & $\%$ \\
\hline Specific heating duty & 2.32 & 2.41 & 3.59 & 3.02 & $\mathrm{MJ}_{\mathrm{th}} \mathrm{kg}^{-1} \mathrm{CO}_{2}$ \\
\hline Specific cooling duty & 3.24 & 3.00 & 3.36 & 3.98 & $\mathrm{MJ}_{\mathrm{th}} \mathrm{kg}^{-1} \mathrm{CO}_{2}$ \\
\hline $\begin{array}{l}\text { Specific electricity } \\
\text { requirements }\end{array}$ & 0.66 & 1.15 & 0.13 & 0.09 & $\mathrm{MJ}_{\mathrm{e}} \mathrm{kg}^{-1} \mathrm{CO}_{2}$ \\
\hline SEPAC & 0.66 & 1.15 & NA & 0.78 & $\mathrm{MJ}_{\mathrm{e}} \mathrm{kg}^{-1} \mathrm{CO}_{2}$ \\
\hline Productivity & 0.35 & 0.32 & 0.40 & & $\mathrm{~kg}_{\text {cO2 }} \mathrm{kg}_{\text {adsorbent }}{ }^{-1} \mathrm{~h}^{-1}$ \\
\hline Total mass of adsorbent & 1437 & 1539 & 1256 & & $\mathrm{t}$ \\
\hline
\end{tabular}

${ }^{a}$ This work; ${ }^{b}[23]$; ${ }^{c}[14]$; ${ }^{d}[16]$; excluding $\mathrm{CO}_{2}$ product compression above 2 bar

The VTCSA configuration with rinse shown in Table 3 captures $85 \%$ of the $\mathrm{CO}_{2}$ emitted by the reference power plant with a final product purity of $95 \% \mathrm{CO}_{2}$ (dry basis), with a specific heat duty of $2.32 \mathrm{MJ}_{\mathrm{th}} \mathrm{kg}^{-1} \mathrm{CO}_{2}$, which is lower than that of the benchmark absorption technology. The typical reboiler duty of conventional absorption process making use of $30 \%$ monoethanolamine (MEA) is around $4 \mathrm{MJ}_{\mathrm{th}} \mathrm{kg}^{-1} \mathrm{CO}_{2}[30]$. Although second generation absorption technologies making use of advanced solvents, like the case included in Table 3, present significant lower energy demand than the MEA case, this is still higher than that of the VTCSA case. Moreover, the specific heat duty of the absorption case is satisfied using steam extracted from the power cycle at near 6 bar and $286^{\circ} \mathrm{C}$, which is partially desuperheated and fed to the reboiler [16]. On the other hand, due to the lower regeneration temperature of the VTCSA process, $80^{\circ} \mathrm{C}$ vs. $120^{\circ} \mathrm{C}$, its heat demand can be satisfied using low-temperature unused waste heat sources. The specific heat duty of the VTCSA process is also significantly lower than that of the TCSA process, due to the milder thermal swing considered in the present work $\left(30-80{ }^{\circ} \mathrm{C}\right.$ versus $\left.30-130^{\circ} \mathrm{C}\right)$. The specific heat duty of the VTCSA process is only 
slightly lower than that of the VTSA process, which uses the same moderate thermal swing $\left(30-80^{\circ} \mathrm{C}\right)$, but which does not make use of steam stripping.

The specific electricity requirements of the VTCSA process are higher than those of the absorption and the TCSA cases, due to the use of vacuum regeneration, but lower than that of the VTSA case, as the latter makes use of higher vacuum levels ( 0.05 bar vs. 0.2 bar).

To make a fair comparison between these technologies, the available SEPAC values have been included in Table 3. This follows the order: VTCSA < Advanced solvent < VTSA. I.e.: the evaluated VTCSA presents lower energy penalty per avoided $\mathrm{CO}_{2}$ than a second generation absorption technology. Moreover, substantial performance improvements can be still be expected from adsorbent development, as it has previously occurred with solvents.

Figure 6 represents the individual contributions of the auxiliary equipment to the specific energy demand of the VTCSA process included in Table 3.
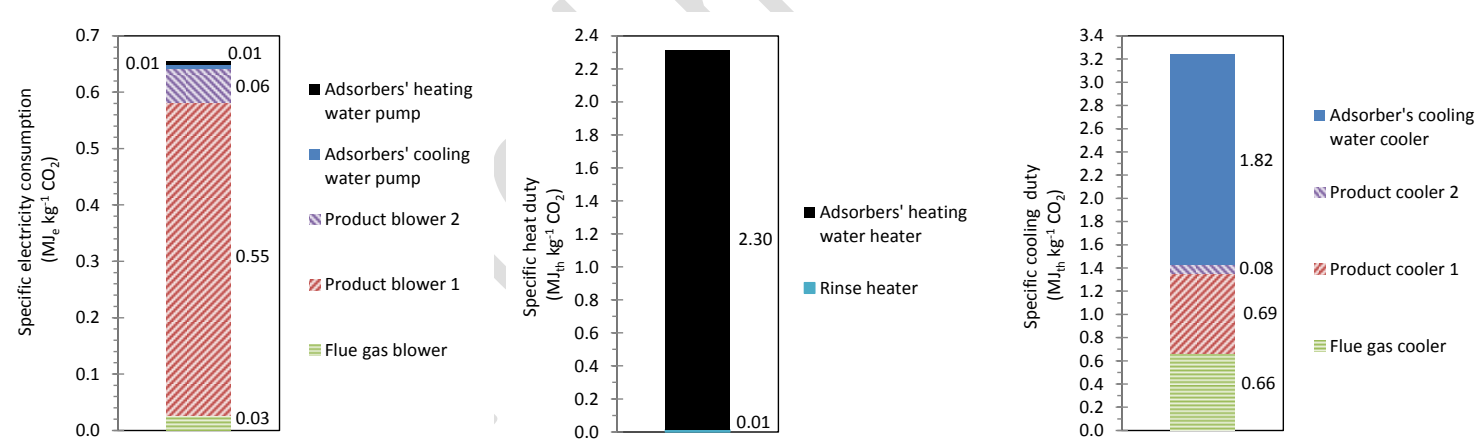

Figure 6. Specific energy demand of the VTCSA process distributed per auxiliary equipment.

As shown in Figure 6, the main electricity consumer of the VTCSA processes is Product blower 1 , which increases the pressure of the product at the adsorber outlet from 0.2 bar up to 1.12 bar, consuming $85 \%$ of the electricity requirements of the VTCSA process. Product blower 2, which increases the pressure of the product (after knocking out the condensate and recirculating part of the product to carry out the rinse step) up to 2.04 bar, goes next, with $9 \%$ of the electricity consumption. The flue gas blower and the pumps used to circulate the 
Accepted for publication in Chemical Engineering Journal. Final version of the article available at: https://doi.org/10.1016/i.cej.2019.122002

cooling and heating water between the adsorbers, account only for $4 \%$ and $1 \%$ of the overall electricity consumption of the process, respectively.

The heat duty of the adsorbers' heating water represents over $99 \%$ of the heat demand of the overall process. Due to the relatively low value of $\mathrm{T}_{H}, 80^{\circ} \mathrm{C}$, low-temperature waste heat can be used to heat the adsorbers, avoiding the need of extracting steam from the steam cycle or the necessity of firing additional fossil fuels to provide the aforementioned heat demand. The heat demand of the rinse heater is very low, representing only $0.6 \%$ of the total heat duty. The cross heat exchanger entails saving $1.3 \mathrm{MJ}_{\mathrm{th}} \mathrm{kg}^{-1} \mathrm{CO}_{2}$.

Lower heat duties, $2.16 \mathrm{MJ}_{\mathrm{th}} \mathrm{kg}^{-1} \mathrm{CO}_{2}$, have been reported for a TSA process making use of zeolite $13 \mathrm{X}$ in a tube-bundle adsorber [21]. However, the hot temperature required in the latter case, $168^{\circ} \mathrm{C}$, would require a high grade heat source. Moreover, the latter value was obtained by simulation using dry flue gas.

The calculated electricity consumption of the VTCSA process is significantly lower than that measured in the VPSA processes evaluated in coal-fired flue gas making use of carbon adsorbents [7, 8]. However, Wang et al. pointed out that the theoretical power consumption was lower than that measured onsite [7]. Note that the power consumption reported by Wang et al. includes only the flue gas blower and the vacuum pumps, but not the compression of the product to any extent. The specific power consumption of Product blower 2, which increases the product pressure from 1.12 to 2.04 bar, accounts for additional $0.06 \mathrm{MJ}_{\mathrm{e}} \mathrm{kg}^{-1} \mathrm{CO}_{2}$, as shown in Figure 6. Moreover, in the work of Wang et al., waste heat from the power plant was used to regenerate the alumina dehydrating unit by heating a fraction of the light product up to $200^{\circ} \mathrm{C}$; and this was not considered as part of the overall energy consumption of the VPSA process [7]. Simulations carried out with dry flue gas and using zeolite $13 \mathrm{X}$ as the adsorbent, point out a lower electricity consumption, of $0.47 \mathrm{MJ}_{\mathrm{e}} \mathrm{kg}^{-1} \mathrm{CO}_{2}$, for a basic 4-step VSA cycle (feed pressurization, adsorption, cocurrent depressurization and countercurrent evacuation) 
with $95 \%$ purity [31]. However, the latter does not include the energy that would be required to dry completely the flue gas or to pressurize the product. Moreover, the higher vacuum levels required, 0.03 bar, might be difficult to achieve in the full scale application.

The VTCSA configuration with cocurrent depressurization evaluated in the present work that achieved $95 \%$ purity and $84 \%$ recovery shows an electricity consumption of $0.71 \mathrm{MJ}_{\mathrm{e}} \mathrm{kg}^{-1} \mathrm{CO}_{2}$, which is slightly higher than that of the VTCSA configuration with rinse included in Table 3. Furthermore, the specific heat duty, $2.38 \mathrm{MJ}_{\text {th }} \mathrm{kg}^{-1} \mathrm{CO}_{2}$, is also slightly higher than that of the cycle configuration with rinse included in Table 3. I.e., the VTCSA configuration with rinse shows better process performance from the recovery and energy consumption point of view. As shown in Table 3, the productivity of the VTCSA process is somewhat lower than that of the TCSA process. The lower productivity compared to the TCSA case is due to the lower superficial velocity of the feed used in the present work $\left(0.27 \mathrm{~m} \mathrm{~s}^{-1} v \mathrm{vs} .0 .36 \mathrm{~m} \mathrm{~s}^{-1}\right)$. Simulations carried out with higher feed velocities (holding constant other design variables) in the initial screening stage failed to meet the recovery constraint. On the other hand, the productivity of the VTCSA process is slightly higher than that of the VTSA process included in Table 3, due to the slightly higher superficial velocity of the feed used in the present work $\left(0.27 \mathrm{~m} \mathrm{~s}^{-1} v \mathrm{vs} 0.26 \mathrm{~m} \mathrm{~s}^{-1}\right)$ and the use of steam stripping.

The productivity of the VTCSA process is high compared to other VTSA processes proposed to carry out post-combustion $\mathrm{CO}_{2}$ capture [32] mainly due to the shorter cycle time and the lower thermal swing used in the present work. Productivity is sometimes expressed in volumetric basis as the net flow rate of $\mathrm{CO}_{2}$ produced by $\mathrm{m}^{3}$ of adsorbent. The volumetric productivity of the VTCSA process is $0.99 \mathrm{~mol} \mathrm{~m}^{-3} \mathrm{~s}^{-1}$, which is much higher than the productivity of $0.44 \mathrm{~mol} \mathrm{~m}^{-3} \mathrm{~s}^{-1}$ reported for the basic 4-step VSA cycle with zeolite 13X [31]. 


\subsection{Parametric study}

A series of simulations of the VTCSA configuration with rinse were carried out using a pressure $P_{L}$ of 0.2 bar and a rinse to feed molar ratio of 0.045 , varying solely the inlet flow rate of steam. The results are summarized in Figure 7.

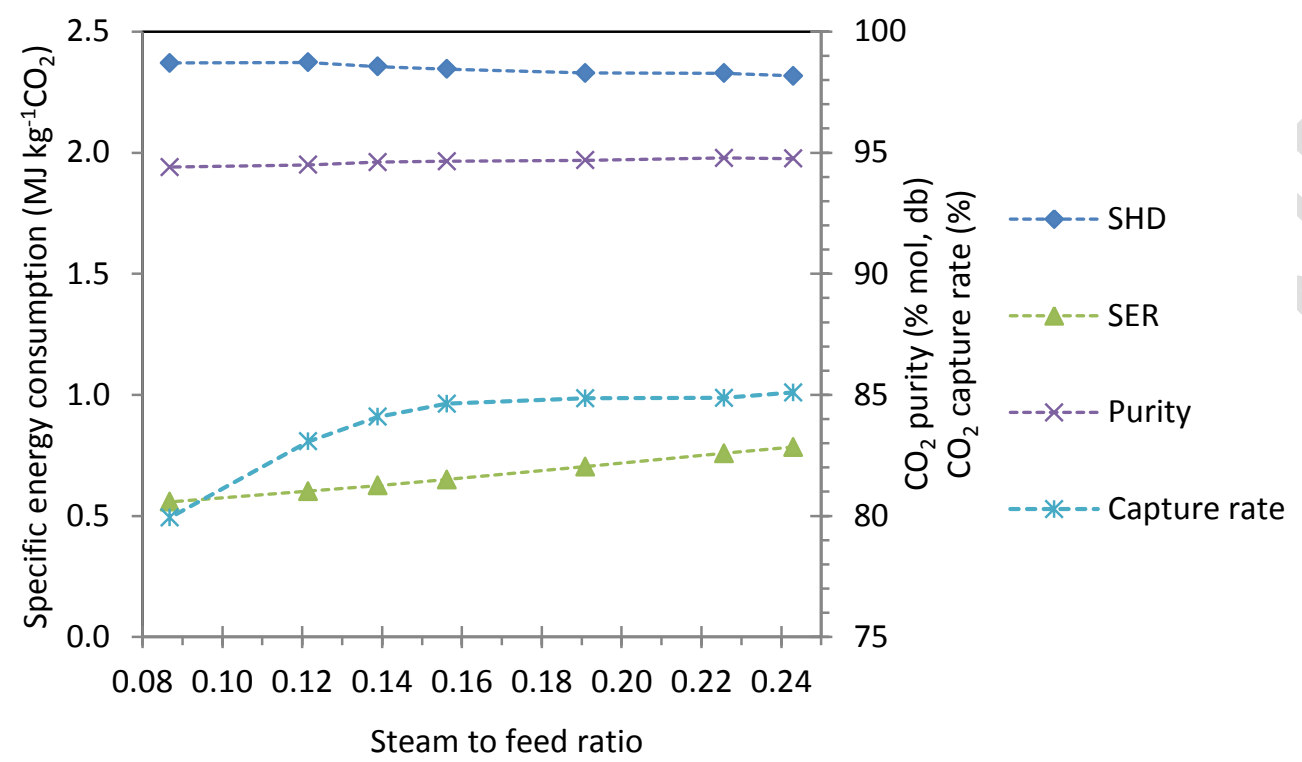

Figure 7. Effect of the steam to feed molar ratio over the main process performance parameters: $\mathrm{CO}_{2}$ purity and capture rate, specific heat duty (SHD), and specific electricity requirements (SER). $\left(\mathrm{P}_{\mathrm{L}}=0.2\right.$ bar; rinse to feed molar ratio: 0.045$)$

As shown in Figure 7, the product purity and the specific heating duty are hardly affected by the inlet flow rate of steam. On the other hand, the specific electricity requirements increase with the flow rate of steam due to the higher consumption of Product blower 1. It is important to highlight that the capture rate drops significantly when the inlet flow rate of steam is reduced below a certain threshold: if the steam to feed molar ratio is reduced below 0.16 , a significant fraction of the adsorbed $\mathrm{CO}_{2}$ remains in the bed, and the target of $85 \%$ capture rate cannot be met anymore. On the other hand, increasing the steam to feed molar ratio above 0.19 has a limited effect over the capture rate because most of the $\mathrm{CO}_{2}$ is already desorbed. This is best shown in Figure 8, which represents the amount of $\mathrm{CO}_{2}$ adsorbed by the end of the production step. 


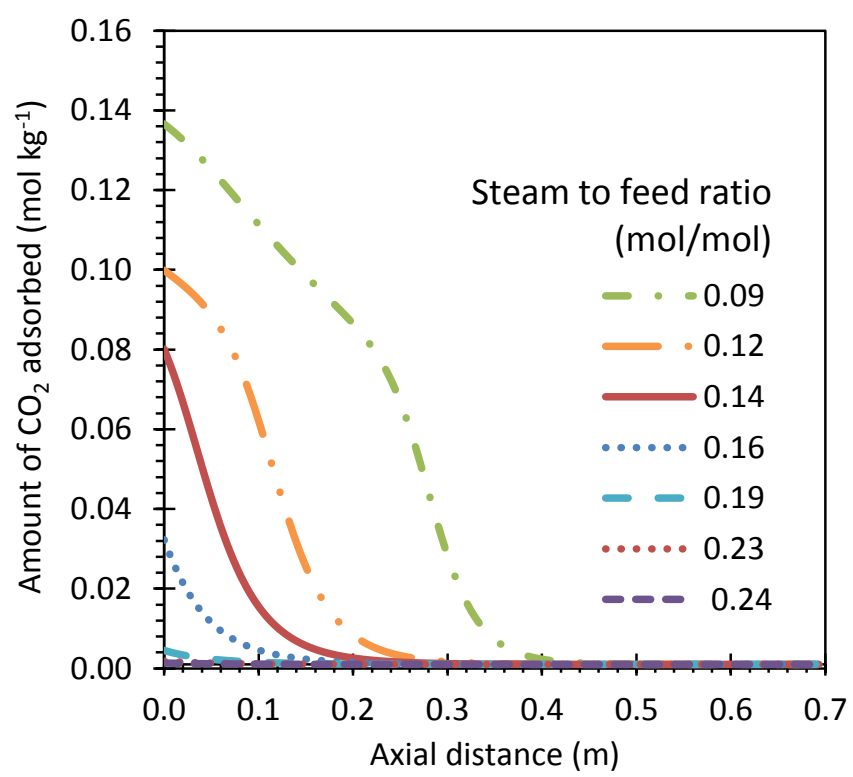

Figure 8. Effect of steam to feed molar ratio over the amount of $\mathrm{CO}_{2}$ adsorbed by the end of the production step.

The $85 \%$ capture threshold corresponds to a steam to $\mathrm{CO}_{2}$ recovered ratio of $0.52 \mathrm{~kg} \mathrm{~kg}^{-1}$, which is somewhat lower than that of the previously evaluated TCSA process [14], $0.62 \mathrm{~kg} \mathrm{~kg}^{-1}$, and significantly lower than that of the VeloxoTherm ${ }^{\mathrm{TM}}$ process [11]. The steam to $\mathrm{CO}_{2}$ recovered ratio of the absorption reference case, $1.22 \mathrm{~kg} \mathrm{~kg}^{-1}$, is also substantially higher. However, in the latter case, the steam consumption represents the largest energy demand of the process. In the case of the VTCSA process evaluated here, the steam consumption refers solely to the steam that is produced in situ from the product condensate and used in direct contact with the adsorbent; additional (waste) heat is still required to heat the adsorbers' heating water.

It is known that the electricity consumption of a VSA processes is strongly affected by the evacuation pressure [33]. Therefore, a priori, increasing the value of $P_{L}$ in the VTCSA process might seem appealing. However, increasing the production pressure has other side effects, like working under conditions closer to the dew point. To evaluate the overall effect of the evacuation pressure over the process performance, a series of simulations were carried out for the VTCSA configuration with rinse up to CSS using an evacuation pressure of 0.3 bar. 
As expected, increasing the evacuation pressure from 0.2 bar to 0.3 bar reduces the overall electricity consumption of the process by $30 \%$. However, the $\mathrm{CO}_{2}$ capture rate is reduced from 85 to $72-76 \%$. This is mainly attributed to the increase in the $\mathrm{H}_{2} \mathrm{O}$ hold-up, which has a double effect: on the one hand there is less $\mathrm{H}_{2} \mathrm{O}$ left in the gas phase to strip the desorbed $\mathrm{CO}_{2}$, and on the other hand the adsorption capacity towards $\mathrm{CO}_{2}$ is reduced by the greater amount of $\mathrm{H}_{2} \mathrm{O}$ coadsorbed. This can be appreciated in Figures 9 and 10, which represent the amount of $\mathrm{H}_{2} \mathrm{O}$ and $\mathrm{CO}_{2}$ adsorbed in the adsorbent bed by the end of the adsorption, the rinse and the production steps, for four simulation runs carried out with two different steam flow rates at the two evacuation pressures evaluated.
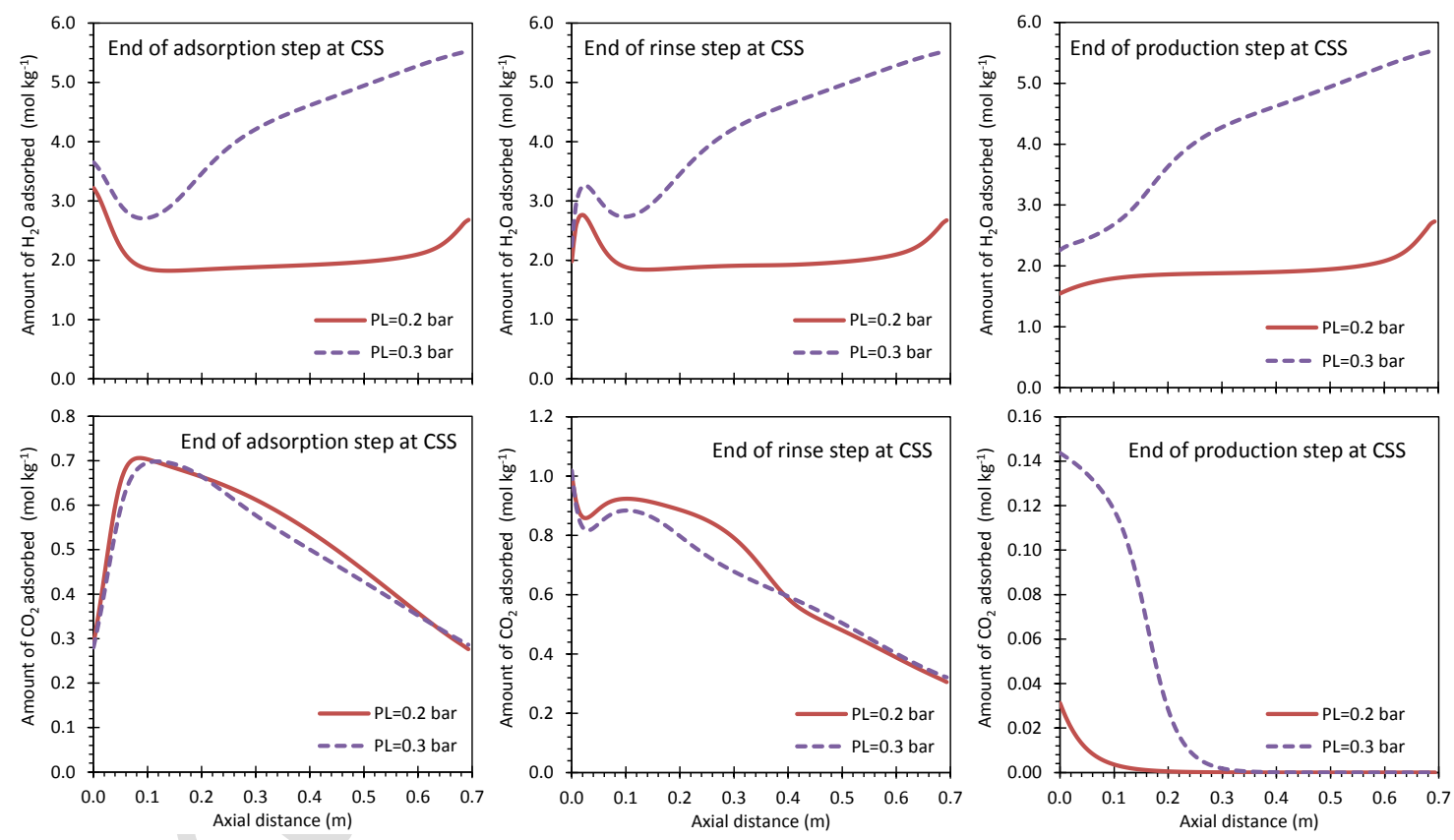

Figure 9. Effect of the evacuation pressure $\left(\mathrm{P}_{\mathrm{L}}\right)$ over the amount of $\mathrm{H}_{2} \mathrm{O}$ and $\mathrm{CO}_{2}$ adsorbed by the end of the adsorption, rinse and production steps (steam to feed molar ratio: 0.16 ; rinse to feed molar ratio: 0.05$)$.

Figure 9, which represents the runs carried out with lower flow rate of inlet steam, shows that a greater amount of $\mathrm{CO}_{2}$ remains adsorbed by the end of the production step at $\mathrm{z}=0$ when the evacuation pressure is increased to 0.3 bar. Note that the amount of $\mathrm{H}_{2} \mathrm{O}$ adsorbed at $\mathrm{z}=\mathrm{L}$ by 
the adsorbent bed is much higher at 0.3 bar than at 0.2 bar. At $\mathrm{z}=0$ the $\mathrm{H}_{2} \mathrm{O}$ loading is lower, because the $\mathrm{H}_{2} \mathrm{O}$ front has not reached the feed end.
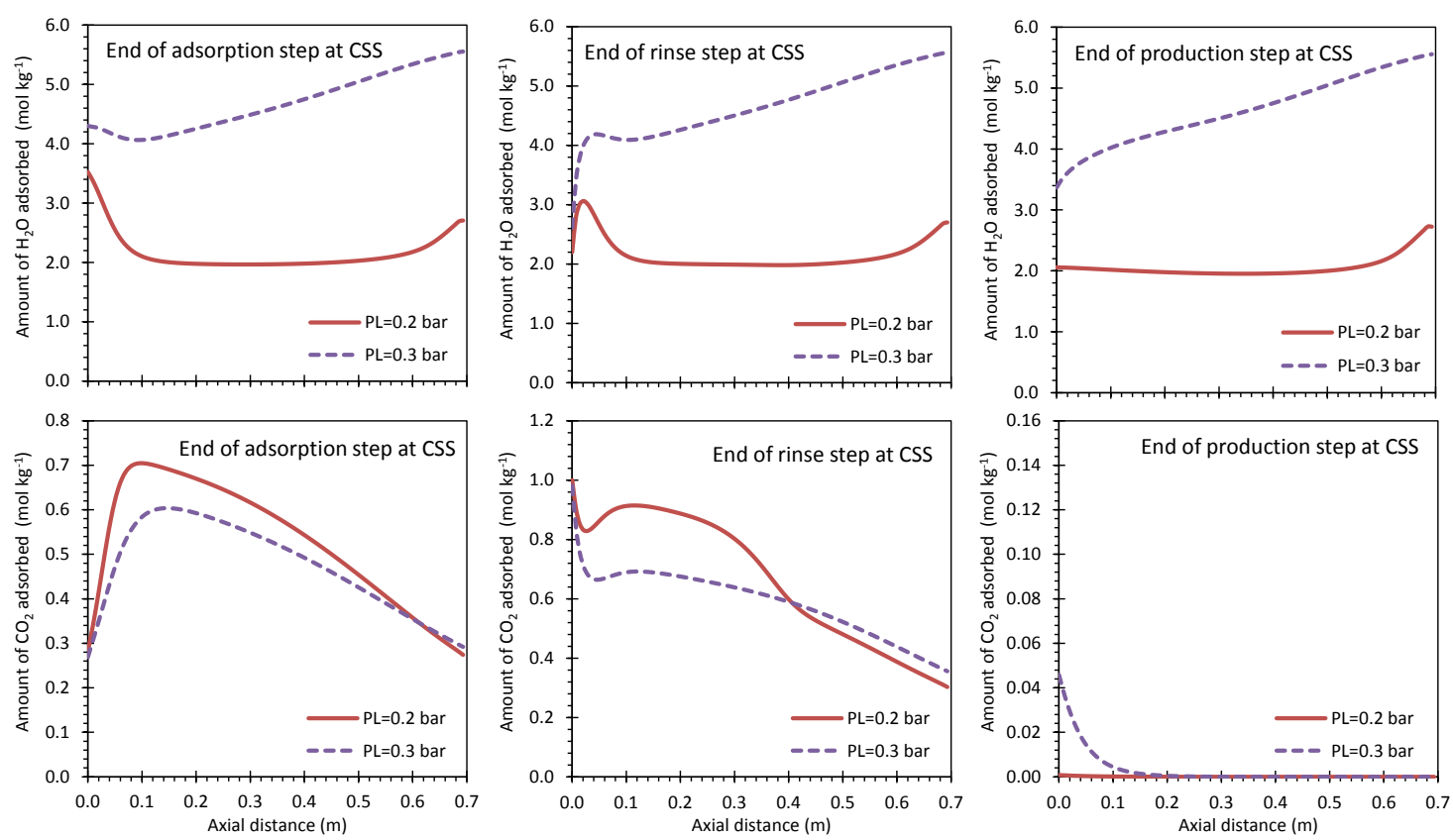

Figure 10. Effect of the evacuation pressure $\left(\mathrm{P}_{\mathrm{L}}\right)$ over the amount of $\mathrm{H}_{2} \mathrm{O}$ and $\mathrm{CO}_{2}$ adsorbed by the end of adsorption, rinse and production steps (steam to feed molar ratio: 0.23 ; rinse to feed molar ratio: 0.05$)$.

Figure 10 represents the runs carried out with higher flow rate of inlet steam. Note that the amount of $\mathrm{H}_{2} \mathrm{O}$ adsorbed at the feed end $(\mathrm{z}=0)$ for the run carried out with $\mathrm{P}_{\mathrm{L}}=0.3$ bar is substantially higher than that of Figure 9 , because the $\mathrm{H}_{2} \mathrm{O}$ front has travelled further. As a consequence, the loading of $\mathrm{CO}_{2}$ at $\mathrm{z}=0$ by the end of the production step is lower than that of Figure 9. However, the $\mathrm{CO}_{2}$ loading by the end of the adsorption and rinse steps is also lower due to the greater amount of $\mathrm{H}_{2} \mathrm{O}$ coadsorbed.

The purity-recovery Pareto points of the VTCSA configuration with rinse that correspond to a $P_{L}$ of 0.3 bar show high purity (up to $99 \%$ ) but, as discussed above, low recovery. To investigate if a reduction in the fraction of product recirculated during the rinse step could increase the capture rate at the expenses of a reduction in purity, a series of simulations were carried out for that configuration up to CSS changing solely the inlet flow rate during the rinse step. Figure 
11 shows that as the rinse flow rate increases, lesser $\mathrm{N}_{2}$ remains in the bed by the end of the rinse step, which means higher $\mathrm{CO}_{2}$ purity, but also that a greater amount of $\mathrm{CO}_{2}$ is lost in the waste stream. Reducing the rinse to feed molar ratio from 0.045 to 0.021 showed to produce only a marginal gain in recovery, insufficient to reach the target.

(a)

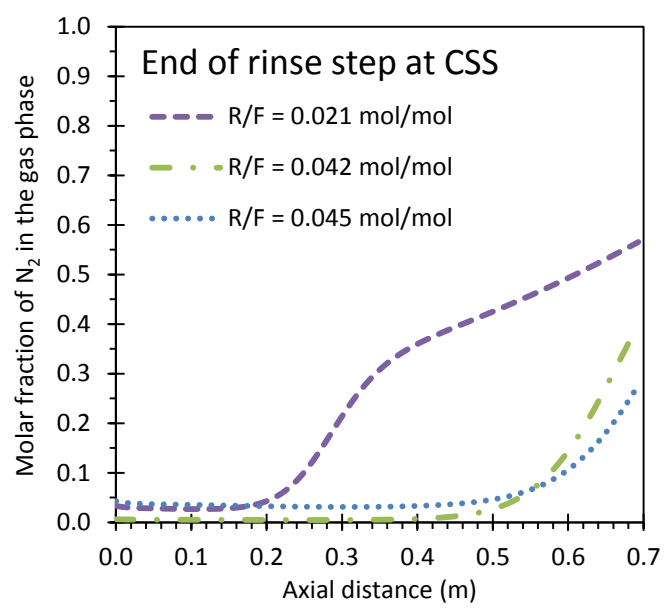

(b)

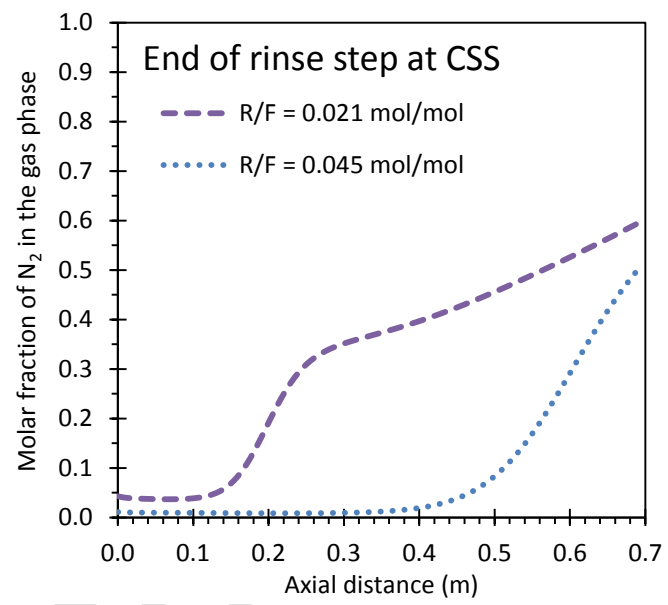

Figure 11. Effect of rinse to feed molar ratio on the profile of the molar fraction of $\mathrm{N}_{2}$ in the gas phase by the end of the rinse step ( $P_{L}=0.3$ bar). Steam to feed molar ratio: (a) 0.23 ; (b) 0.16 . In the case of the VTCSA configuration with cocurrent depressurization, the influence of the intermediate pressure over the process performance parameters was investigated. In order to do so, a series of simulations were carried out up to CSS varying solely the flow rate of waste gas extracted from the bed during the cocurrent depressurization step. The results are summarized in Figure 12. 


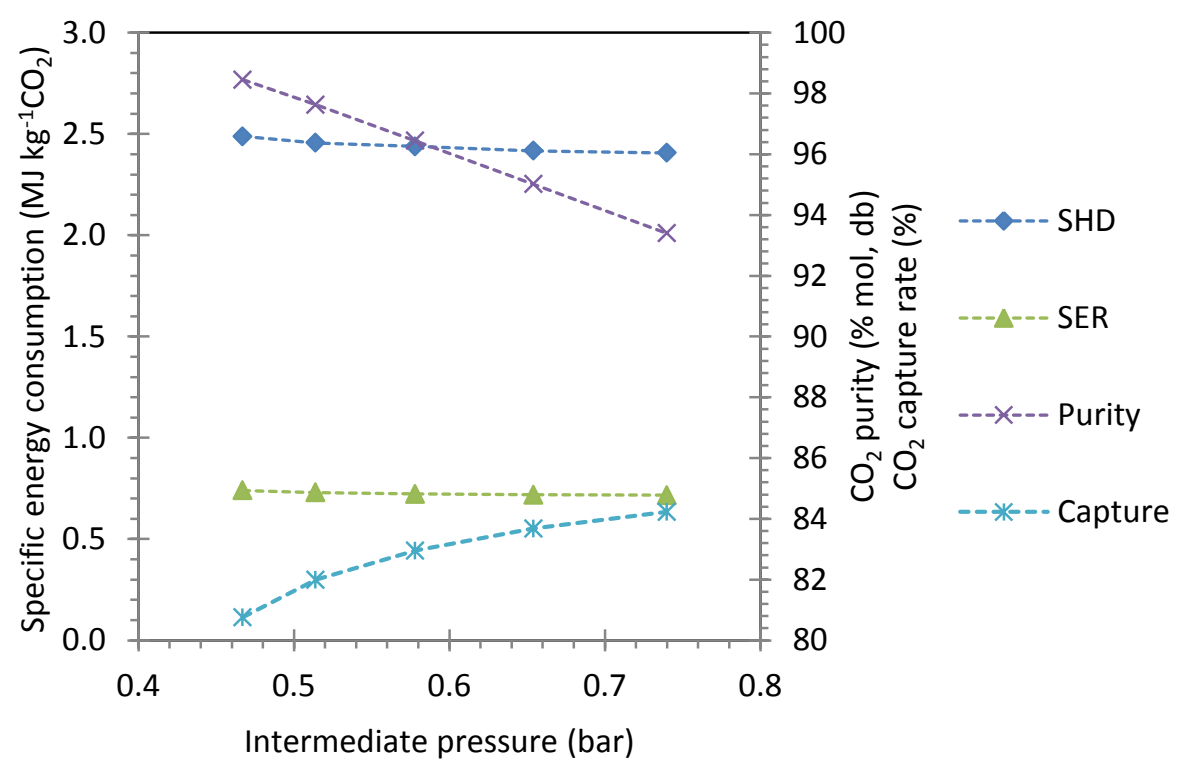

Figure 12. Effect of intermediate pressure $\left(\mathrm{P}_{1}\right)$ on process performance parameters: $\mathrm{CO}_{2}$ purity and capture rate, specific heat duty (SHD), and specific electricity requirements (SER). $\left(P_{L}=0.2\right.$ bar; Steam to feed molar ratio: 0.23$)$.

As usual, the $\mathrm{CO}_{2}$ capture rate and the $\mathrm{CO}_{2}$ purity of the product follow opposite trends: as $\mathrm{P}_{\mathrm{I}}$ increases, the capture rate increases because less $\mathrm{CO}_{2}$ is lost with the waste stream; however, the purity decreases, as more $\mathrm{N}_{2}$ remains in the bed by the end of the step. Figure 12 shows that the specific energy consumption is hardly affected by the intermediate pressure level. In fact, the absolute energy consumption increases slightly with pressure, but due to the gain in recovery, the specific energy consumption decreases slightly.

\section{Conclusions}

Two alternative configurations of a multibed heat integrated vacuum, temperature and concentration swing adsorption post-combustion $\mathrm{CO}_{2}$ capture process have been designed and evaluated through dynamic simulation up to cyclic steady state. In this process the adsorbent is a biomass-based carbon regenerated using superheated steam at $80^{\circ} \mathrm{C}$ in direct contact with the adsorbent at subatmospheric pressures. The two configurations evaluated differ in the series of steps carried out sequentially: one includes a rinse step with a fraction of the 
product, and the other includes a cocurrent depressurization step to an intermediate pressure.

The VTCSA configuration with rinse is able to meet the $95 \%$ purity and $85 \%$ recovery constrains using an evacuation pressure of 0.2 bar and a steam to feed molar ratio above 0.16 . On the other hand, the configuration with cocurrent depressurization is able to provide a $\mathrm{CO}_{2}$ product with high purity, but fails to meet the $85 \%$ recovery constraint in the operation range evaluated.

The specific heat duty of the post-combustion VTCSA process that satisfies the $95 \%$ purity and $85 \%$ recovery constrains is $2.32 \mathrm{MJ}_{\mathrm{th}} \mathrm{kg} \mathrm{CO}_{2}$, which is lower than that of the benchmark absorption technology. Moreover, due to the relatively low temperature at which the adsorbent needs to be heated, $80^{\circ} \mathrm{C}$, the heat demand of the process might be satisfied using waste heat. This is an important advantage, as the regeneration of chemical solvents requires the extraction of steam from the power cycle, which reduces the plant efficiency, or the generation of steam at temperatures above $120^{\circ} \mathrm{C}$ in an independent boiler unit, with the associated further fuel consumption.

On the other hand, the specific electricity requirements of the VTCSA process, $0.66 \mathrm{MJ}_{\mathrm{e}} \mathrm{kg}^{-1}$, are higher than the benchmark technology due to the use of vacuum to regenerate the adsorbent.

Assuming that the heat demand of the VTCSA process can be entirely satisfied using waste heat, the specific energy penalty of avoided $\mathrm{CO}_{2}$ of the VTCSA process is lower than that of a second generation absorption technology. Further performance improvements can still be expected from adsorbent development.

\section{Nomenclature}

CCUS carbon capture, use and/or storage

CSS cyclic steady state

D cocurrent depressurization step 
adsorber at $T_{1}$

D2 second half of the cocurrent depressurization step; heating water enters the adsorber at $\mathrm{T}_{\mathrm{H}}$

$\mathrm{db}$ dry basis

Ideal Adsorbed Solution theory

length of the tubes packed with the adsorbent

actual flow rate of cooling water used by the adsorbers (continuous flow)

monoethanolamine

$m_{h w}$

actual flow rate of heating water used by the adsorbers (discontinuous flow)

$<m_{h w}>$

flow rate of heating water used by the adsorbers averaged by cycle time

NEO

net electric output of the power plant $\left(\mathrm{MW}_{\mathrm{e}}\right)$

$P_{H}$

high pressure; pressure of the decarbonized flue gas discharged to the stack

$P_{1}$

intermediate pressure reached by the end of the cocurrent depressurization step: $P_{L}<P_{l}<P_{H}$

$P_{L}$

low pressure; pressure of the production step

pressure swing adsorption

pressure and temperature swing adsorption

$\mathrm{R}$

R1

R2

ref
Rinse step

first half of the rinse step; inlet streams enter the adsorber at $T_{1}$

second half of the rinse step; inlet streams enter the adsorber at $T_{H}$

reference power plant without capture 
SHD specific heat duty of the post-combustion $\mathrm{CO}_{2}$ capture process $\left(\mathrm{MJ}_{\mathrm{th}} \mathrm{kg}^{-1} \mathrm{CO}_{2}\right)$

SEPAC Specific energy penalty of avoided $\mathrm{CO}_{2}\left(\mathrm{MJ}_{\mathrm{e}} \mathrm{kg}^{-1} \mathrm{CO}_{2}\right)$

$\left(\mathrm{MJ}_{\mathrm{e}} \mathrm{kg}^{-1} \mathrm{CO}_{2}\right)$

$T_{H} \quad$ high temperature; inlet temperature of steam and heating water

$T_{1} \quad$ Intermediate temperature: $T_{L}<T_{l}<T_{H} ;$ temperature of inlet streams during the rinse and cocurrent depressurization steps

$T$ low temperature; inlet temperature of cooling water during the pressurization and adsorption steps

TSA temperature swing adsorption

TCSA temperature and concentration swing adsorption

VPSA vacuum and pressure swing adsorption

VTSA vacuum and temperature swing adsorption

VTCSA vacuum, temperature and concentration swing adsorption axial dimension of the adsorber

$\phi_{\mathrm{CO}_{2}}$ emitted flow of $\mathrm{CO}_{2}$ in $\mathrm{kg} \mathrm{s}^{-1}$

\section{Acknowledgements}

M.G.P. acknowledges the Spanish MINECO the award of a Ramon y Cajal contract (RyC-201517516).

\section{Funding}

This research did not receive any specific grant from funding agencies in the public, commercial, or not-for-profit sectors. 


\section{Declarations of interest}

None

\section{References}

[1] IPCC, Global warming of $1.5^{\circ} \mathrm{C}$ : an IPCC Special Report on the impacts of global warming of $1.5^{\circ} \mathrm{C}$ above pre-industrial levels and related global greenhouse gas emission pathways, in the context of strengthening the global response to the threat of climate change, sustainable development, and efforts to eradicate poverty, IPCC Special Reports, 2018.

[2] K. Stéphenne, Start-up of world's first commercial post-combustion coal fired CCS project: contribution of Shell Cansolv to SaskPower Boundary Dam ICCS project, Energy Procedia 63 (2014) 6106-6110.

[3] O. Miyamoto, C. Maas, T. Tsujiuchi, M. Inui, T. Hirata, H. Tanaka, T. Yonekawa, T. Kamijo, KM CDR Process ${ }^{\mathrm{TM}}$ project update and the new novel solvent development, Energy Procedia 114 (2017) 5616-5623.

[4] ICCSKC, The Shand CCS feasibility study. Public report, International CCS Knowledge Centre, 2018.

[5] M. Khurana, S. Farooq, Integrated adsorbent process optimization for minimum cost of electricity including carbon capture by a VSA process, AIChE J 65 (2019) 184-195.

[6] M. Ishibashi, H. Ota, N. Akutsu, S. Umeda, M. Tajika, J. Izumi, A. Yasutake, T. Kabata, Y. Kageyama, Technology for removing carbon dioxide from power plant flue gas by the physical adsorption method, Energ Convers Manage 37 (1996) 929-933.

[7] L. Wang, Y. Yang, W. Shen, X. Kong, P. Li, J. Yu, A.E. Rodrigues, $\mathrm{CO}_{2}$ capture from flue gas in an existing coal-fired power plant by two successive pilot-scale VPSA units, Ind Eng Chem Res 52 (2013) 7947-7955.

[8] D. Wawrzyńczak, I. Majchrzak-Kucęba, K. Srokosz, M. Kozak, W. Nowak, J. Zdeb, W. Smółka, A. Zajchowski, The pilot dual-reflux vacuum pressure swing adsorption unit for $\mathrm{CO}_{2}$ capture from flue gas, Sep Purif Technol 209 (2019) 560-570.

[9] T. Okumura, K. Yoshizawa, S. Nishibe, H. Iwasaki, M. Kazari, T. Hori, Parametric testing of a pilot-scale design for a moving-bed $\mathrm{CO}_{2}$ capture system using low-temperature steam, Energy Procedia 114 (2017) 2322-2329.

[10] SRI, Pilot-scale evaluation of an advanced carbon sorbent-based process for postcombustion carbon capture, 2016 NETL Project Review Meeting, 2016.

[11] D. Greeson, NRG $\mathrm{CO}_{2}$ NCEPT - Confirmation of the novel cost-effective emerging postcombustion technology. DE-FE0026581 Final technical report, 2016.

[12] S.-H. Jo, Y.C. Park, J.-H. Moon, S. Lee, S.P. Han, C.-K. Yi, Heat integration of KIERDRY process with a power plant using gPROMS, Energy Procedia 114 (2017) 6660-6665.

[13] M. Khurana, S. Farooq, Integrated adsorbent-process optimization for carbon capture and concentration using vacuum swing adsorption cycles, AIChE J 63 (2017) 2987-2995.

[14] M.G. Plaza, F. Rubiera, C. Pevida, Evaluating the feasibility of a TSA process based on steam stripping in combination with structured carbon adsorbents to capture $\mathrm{CO}_{2}$ from a coal power plant, Energy Fuels 31 (2017) 9760-9775. 
[15] M. Gawryś, P. Fastyn, J. Gawłowski, T. Gierczak, J. Niedzielski, Prevention of water vapour adsorption by carbon molecular sieves in sampling humid gases, J Chromatogr A 933 (2001) 107-116.

[16] H.M. Kvamsdal, G. Haugen, J. Brown, P. Wolbers, R.J. Drew, P. Khakharia, J.G.M.S. Monteiro, E.L.V. Goetheer, J. Middelkamp, M. Kanniche, A.J. Sirvent, Reference Case and Test Case for Benchmarking of HiPerCap Technologies, Energy Procedia 114 (2017) 2642-2657.

[17] M.G. Plaza, A.S. González, J.J. Pis, F. Rubiera, C. Pevida, Production of microporous biochars by single-step oxidation: Effect of activation conditions on $\mathrm{CO}_{2}$ capture, Appl Energy 114 (2014) 551-562.

[18] M.G. Plaza, I. Durán, N. Querejeta, F. Rubiera, C. Pevida, Experimental and simulation study of adsorption in postcombustion conditions using a microporous biochar. 1. $\mathrm{CO}_{2}$ and $\mathrm{N}_{2}$ adsorption, Ind Eng Chem Res 55 (2016) 3097-3112.

[19] M.G. Plaza, I. Durán, N. Querejeta, F. Rubiera, C. Pevida, Experimental and simulation study of adsorption in postcombustion conditions using a microporous biochar $2 . \mathrm{H}_{2} \mathrm{O}, \mathrm{CO}_{2}$, and $\mathrm{N}_{2}$ adsorption, Ind Eng Chem Res 55 (2016) 6854-6865.

[20] M.G. Plaza, I. Durán, F. Rubiera, C. Pevida, Adsorption-based process modelling for postcombustion $\mathrm{CO}_{2}$ capture, Energy Procedia 114 (2017) 2353-2361.

[21] G.S. Duarte, B. Schürer, C. Voss, D. Bathen, Modeling and simulation of a tube bundle adsorber for the capture of $\mathrm{CO}_{2}$ from flue gases, Chemie Ingenieur Technik 88 (2016) 336-345.

[22] L. Joss, M. Gazzani, M. Mazzotti, Rational design of temperature swing adsorption cycles for post-combustion $\mathrm{CO}_{2}$ capture, Chem Eng Sci 158 (2017) 381-394.

[23] M.G. Plaza, F. Rubiera, Evaluation of a novel multibed heat-integrated vacuum and temperature swing adsorption post-combustion $\mathrm{CO}_{2}$ capture process, Appl Energy 250 (2019) 916-925.

[24] M.G. Plaza, A.S. González, C. Pevida, F. Rubiera, Influence of water vapor on $\mathrm{CO}_{2}$ adsorption using a biomass-based carbon, Ind Eng Chem Res 53 (2014) 15488-15499.

[25] S. Sjostrom, H. Krutka, Evaluation of solid sorbents as a retrofit technology for $\mathrm{CO}_{2}$ capture, Fuel 89 (2010) 1298-1306.

[26] A.L. Myers, J.M. Prausnitz, Thermodynamics of mixed-gas adsorption, AIChE J 11 (1965) 121-127.

[27] S.W. Rutherford, Probing the Mechanism of Water Adsorption in Carbon Micropores with Multitemperature Isotherms and Water Preadsorption Experiments, Langmuir 22 (2006) 99679975.

[28] D.F. Fairbanks, C.R. Wilke, Diffusion Coefficients in Multicomponent Gas Mixtures, Ind Eng Chem 42 (1950) 471-475.

[29] R.B. Bird, W.E. Stewart, E.N. Lightfoot, Transport Phenomena, John Wiley \& Sons, New York, 1960.

[30] K. Li, W. Leigh, P. Feron, H. Yu, M. Tade, Systematic study of aqueous monoethanolamine (MEA)-based $\mathrm{CO}_{2}$ capture process: Techno-economic assessment of the MEA process and its improvements, Appl Energy 165 (2016) 648-659.

[31] R. Haghpanah, R. Nilam, A. Rajendran, S. Farooq, I.A. Karimi, Cycle synthesis and optimization of a VSA process for postcombustion $\mathrm{CO}_{2}$ capture, AIChE J 59 (2013) 4735-4748. 
[32] L. Wang, Z. Liu, P. Li, J. Yu, A.E. Rodrigues, Experimental and modeling investigation on post-combustion carbon dioxide capture using zeolite 13X-APG by hybrid VTSA process, Chem Eng J 197 (2012) 151-161.

[33] J. Zhang, P.A. Webley, P. Xiao, Effect of process parameters on power requirements of vacuum swing adsorption technology for $\mathrm{CO}_{2}$ capture from flue gas, Energ Convers Manage 49 (2008) 346-356. 